Article

\title{
Aircraft Takeoff Performance in a Changing Climate for Canadian Airports
}

\author{
Yijie Zhao * and Laxmi Sushama
}

Department of Civil Engineering and Applied Mechanics and Trottier Institute for Sustainability in Engineering and Design, McGill University, Montreal, QC H3A 0C3, Canada; laxmi.sushama@mcgill.ca

* Correspondence: yijie.zhao@mail.mcgill.ca

Received: 15 March 2020; Accepted: 15 April 2020; Published: 21 April 2020

\begin{abstract}
Temperature and wind are major meteorological factors that affect the takeoff and landing performance of aircraft. Warmer temperatures and the associated decrease in air density in future climate, and changes to crosswind and tailwind, can potentially impact aircraft performance. This study evaluates projected changes to aircraft takeoff performance, in terms of weight restriction days and strong tailwind and crosswind occurrences, for 13 major airports across Canada, for three categories of aircraft used for long-, medium- and short-haul flights. To this end, two five-member ensembles of transient climate change simulations performed with a regional climate model, for Representative Concentration Pathway (RCP) 4.5 and 8.5 scenarios, respectively, are analyzed. Results suggest that the projected increases in weight restriction days associated with the increases in daily maximum temperatures vary with aircraft category and airfield location, with larger increases noted for airfields in the south central regions of Canada. Although avoiding takeoff during the warmest period of the day could be a potential solution, analysis focused on the warmest and coolest periods of the day suggests more weight restriction hours even during the coolest period of the day, for these airfields. Though RCP8.5 in general suggests larger changes to weight restriction hours compared to RCP4.5, the differences between the two scenarios are more prominent for the coolest part of the day, as projected changes to daily minimum temperatures occur at a much faster rate for RCP8.5 compared to RCP4.5, and also due to the higher increases in daily minimum temperatures compared to maximum temperatures. Both increases and decreases to crosswind and tailwind are projected, which suggest the need for detailed case studies, especially for those airfields that suggest increases. This study provides useful preliminary insights related to aircraft performance in a warmer climate, which will be beneficial to the aviation sector in developing additional analysis and to support climate change adaptation-related decision-making.
\end{abstract}

Keywords: climate change; aviation; aircraft performance; maximum daily temperature; weight restriction day; crosswind; tailwind

\section{Introduction}

Projected changes to the mean and/or variability of climatic variables and extreme events in future climate [1] can impact the aviation sector, including aircraft ground and air operations. For instance, more than 30\% of reported aviation accidents in North America during the 1990-2006 period were weather related, either directly or indirectly [2]. Besides, according to the Bureau of Transportation Statistics [3], approximately $40 \%$ of the total delay minutes are weather related. Aircraft takeoff performance, which primarily refers to the ability of an aircraft to take off in a short distance, is mainly dependent on air density and wind characteristics [4]. Higher air temperatures in the future climate and the associated decrease in air density can reduce the lift generated during takeoff [4]. Besides, it should be noted that air density at constant temperature is lower for high altitude airfields due 
to lower atmospheric pressure. Lower air density refers to poor aircraft takeoff performance and suggests the need for greater takeoff speed and longer accelerating/takeoff distance. Reducing the gross weight by removing fuel or passengers and cargo is usually used to solve this problem. Another factor that contributes to aircraft takeoff performance is wind, with high crosswinds leading to significant decreases in the controllability of aircraft during takeoff [4]. Furthermore, headwind and tailwind along the runway also play an important role during takeoff. For example, a headwind that is $10 \%$ of the takeoff speed reduces the takeoff distance by approximately $10 \%$, while a same speed tailwind increases the takeoff distance by around 21\% [4]. Many accidents, such as overrun, have happened for tailwind greater than 10 knots [5]. Given the above, changes to wind characteristics in the future might influence many aspects of runway requirements.

So far, few studies have investigated the effects of climate change on aircraft performance. Coffel and Horton [6] studied the impact of rising daily maximum temperature for the May to September period for four major airports in the United States, which suggests more days with weight restriction for aircraft used for short- to medium-haul flights, such as Boeing 737-800. Coffel et al. [7] extended their study to 19 major airports around the world and concluded that $10-30 \%$ of flights departing at the time of daily maximum temperature may require some weight restriction below their maximum takeoff weights. Zhou et al. [8] investigated the takeoff distance for Boeing 737-800 for 30 major international airports, and indicated that the average takeoff distance in summer will increase by $1.6 \%$ to $11 \%$ by the end of the century (2071-2100) for the Representative Concentration Pathway (RCP) 8.5 emissions scenario. Zhou et al. [9] studied weight restriction days for airfields in China for the case of Boeing 737-800 and reported that weight restriction days will increase significantly at three airports located in the southern, central, and high-elevation regions of China. Gratton et al. [10] analyzed the historic changes in temperature and wind conditions and their impacts on aircraft performance at 10 Greek airports. They reported a clear impact of rising temperatures in terms of a steady increase in takeoff distance at airports with longer runways and significant weight restrictions at airports with shorter runways. Climate change impacts on clear-air turbulence and therefore on aviation were addressed in a number of recent studies [11-15]. Williams and Joshi [14], using climate model simulations, were the first to suggest significant increases in clear-air turbulence strength and frequency for the transatlantic flight corridor for doubled carbon dioxide concentration in the atmosphere. This has important implications, such as longer journey times and, hence, increases in fuel consumption and emissions.

According to Canada's Changing Climate Report [16], the average surface temperature for Canada has increased by $1.7^{\circ} \mathrm{C}$ since 1948 , approximately double the rate as that of the world as a whole. The annual and the seasonal mean daily maximum temperature has increased since the beginning of this century across Canada [17]. Furthermore, analysis of projected changes to temperature extremes for the 2040-2069 period for the SRES (Special Report on Emissions Scenarios) A2 scenario by Jeong et al. [18], using Regional Climate Model (RCM) ensembles, suggests increases in extreme temperature events, particularly for southern Canada. Large spatial variability in projected changes to annual maximum three-hourly wind speed, with increases for northern regions of Canada and decreases elsewhere, was reported by Jeong and Sushama [19].

Given the above changes, the main purpose of this study is to investigate the impact of climate change, more specifically projected changes to daily maximum temperature and wind characteristics, on aircraft takeoff performance at 13 major airports across Canada, using outputs from an RCM for different emission scenarios. The rest of the paper is organized as follows. Section 2 describes the RCM, simulations and observed dataset used in this study. Section 3 discusses the methodology and relation between aircraft takeoff performance and climatic variables and associated thresholds. Section 4 presents the validation of the RCM-simulated aviation-related climatic variables, their projected changes and implications for aircraft takeoff in the future climate. Summary and conclusions of the study are provided in Section 5 . 


\section{Model, Simulations and Observation Data}

\subsection{Model and Simulations}

The RCM used in this study is a limited area version of the Global Environmental Multiscale (GEM) model [20], which is used for numerical weather prediction by Environment and Climate Change Canada (ECCC). GEM employs semi-Lagrangian transport and a (quasi) fully implicit stepping scheme. In its fully elastic non-hydrostatic formulation [21], GEM uses a vertical coordinate based on hydrostatic pressure [22]. The convection schemes of Kain and Fritsch [23] and Bélair et al. [24], for deep and shallow convection, respectively, are used. The resolvable large-scale precipitation is calculated following Sundqvist et al. [25]. Radiation is parameterized by the correlated-K solar and terrestrial radiation of $\mathrm{Li}$ and Barker [26]. The planetary boundary layer follows Benoit et al. [27] and Delage [28], with some modifications as described in Zadra et al. [29]. The Canadian land-surface scheme (CLASS) version 3.5 [30], allowing a flexible number of soil layers and thicknesses, is used to represent land processes and lakes are represented by the one-dimensional Flake model [31]. A detailed description of GEM can be found in Diro and Sushama [32].

The experimental domain of the model covers the Pan-Arctic region (i.e., region north of the forty-ninth parallel), at $0.5^{\circ}$ horizontal resolution (Figure 1a). It consists of $172 \times 172$ grid cells and has 76 levels in the vertical. The analysis presented in this study covers only Canada though (Figure 1a). The atmospheric lateral boundary conditions are obtained from the European Centre for Medium-Range Weather Forecast (ECMWF) Re-Analysis (ERA)-Interim data [33], and from two five-member ensembles of second-generation Canadian Earth System Model (CanESM2) [34], corresponding to RCP 4.5 and 8.5 scenarios. The CanESM2 driven GEM simulations span the 1981-2100 period, while the ERA-Interim-driven GEM simulation covers the current 1981-2010 period and is used to validate the model. The above simulations will be referenced to as GEM-CanESM2 and GEM-ERAInterim in the remainder of the paper. It must be noted that the 1981-2005 period of the GEM-CanESM2 simulations for RCP 4.5 and 8.5 scenarios are exactly the same.

(a)

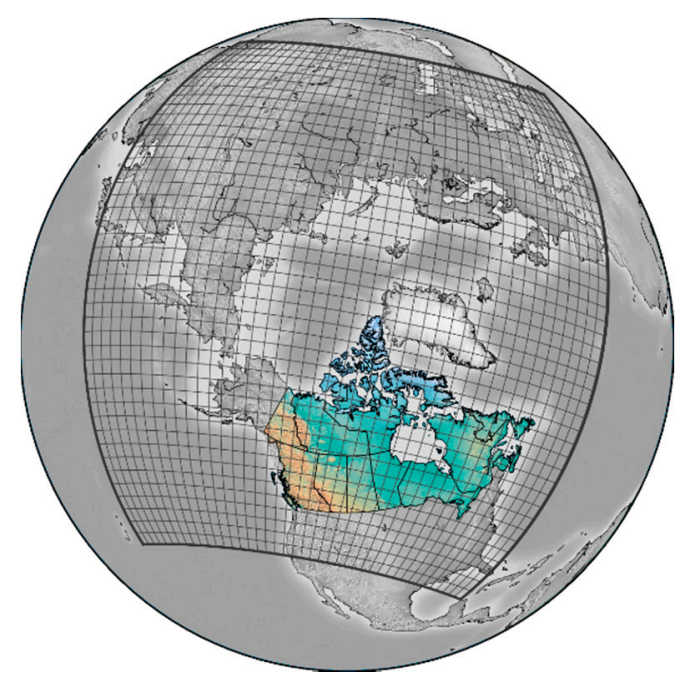

Figure 1. Cont. 
(b)

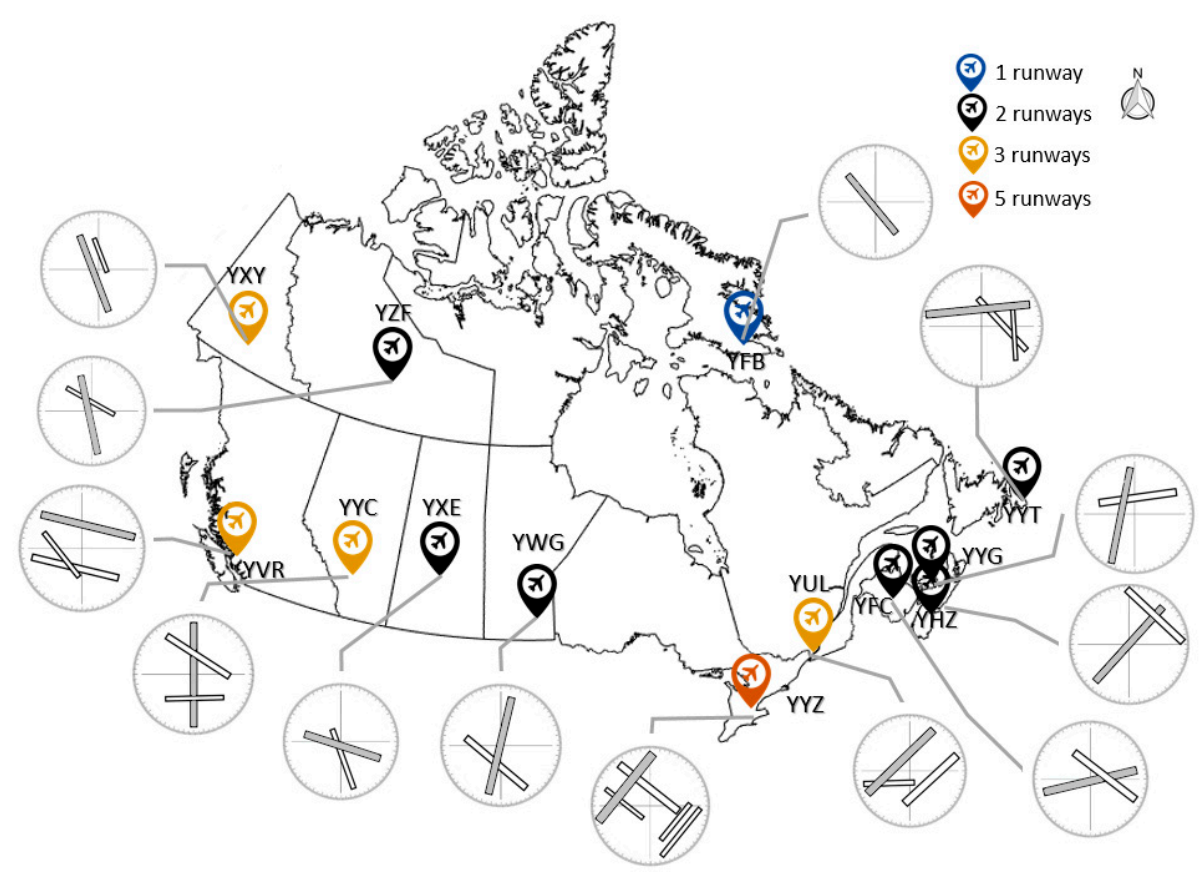

Figure 1. (a) Model experimental domain consisting of $172 \times 172$ grid points; every fifth grid point is shown. The region of analysis (Canada) considered in this study has topography shown in color. (b) Runways and their orientations for the 13 airfields considered in this study. The longest runway at each airport is shown shaded. The colors indicate the number of runways (see legend).

\subsection{Observation Data}

Gridded datasets and point observations are used for model validation purposes. The point observations are obtained from Environment Canada [35]. For validating GEM-ERAInterim simulated temperature and wind fields, ERA-Interim reanalysis [33] at $0.75^{\circ}$ and six-hourly resolution, as well as the newly released global reanalysis ERA5 at $0.25^{\circ}$ [36] and one-hourly resolution for the 1981-2010 period, are used. Besides, hourly wind roses from point observations at the studied airfields, expressed in $10 \mathrm{~s}$ of degrees, and ERA 5 are used to validate the wind speed and directions from model simulations (three-hourly) for the 1981-2010 period. It should be noted that wind point observations are very sensitive to changes in anemometer height and location, and changes in these factors can lead to large changes in the wind rose [37]. This can lead to some differences between observations and reanalysis or model simulations, in addition to the differences that may arise when comparing point observations with grid cell values.

\section{Methodology}

\subsection{Definitions, Thresholds and Airfields}

To assess the impact of climate change on aircraft takeoff performance, this study focuses on weight restriction days and strong tailwind and crosswind occurrences, for 13 airports situated across Canada (Figure 1b) in different climatic regions: Erik Nielsen Whitehorse International Airport (YXY), Vancouver International Airport (YVR), Calgary International Airport (YYC), Yellowknife Airport (YZF), John G. Diefenbaker International Airport (YXE), Winnipeg James Armstrong Richardson International Airport (YWG), Iqaluit Airport (YFB), Lester B. Pearson International Airport (YYZ), Pierre Elliott Trudeau International Airport (YUL), Fredericton International Airport (YFC), Charlottetown Airport (YYG), Robert L. Stanfield International Airport (YHZ) and St. John's International Airport (YYT). The runway lengths and altitudes for these airfields are shown in Table 1. Runway details (i.e., orientation 
and the number of runways) are given in Figure 1 for the same airfields. These airfields include the top three busiest Canadian airports (YYZ, YVR, and YUL) that have intercontinental flights, and an additional eight international airports with flights mostly connecting North and South Americas and two smaller airports with just domestic flights. The types of aircraft used for the above mentioned long-, medium- and short-haul flights will be referred to as category 1, 2 and 3, respectively, with aircraft's maximum takeoff weight (MTOW) $>90,000 \mathrm{Kg}$ for category 1, 18,000 Kg $<$ MTOW $<90,000 \mathrm{Kg}$ for category 2 and MTOW $<18,000 \mathrm{Kg}$ for category 3. Table 2 shows the annual itinerant movements for the three aircraft categories as well as the fraction of total flights that use these 3 categories of aircraft at the studied airfields.

Table 1. Runway characteristics for the 13 Canadian airports considered in this study, along with the International Air Transport Association (IATA) code. Data obtained from Nav Canada airports chart. Primary runway length are for the longest runway at the airport; crosswind runways are also provided; and they are used during unfavorable conditions of the primary runway.

\begin{tabular}{ccccc}
\hline IATA Code & Location & Elevation $(\mathbf{f t})$ & Longest Runway $(\mathbf{f t})$ & Crosswind Runway $(\mathbf{f t})$ \\
\hline YXY & Whitehorse & 2317 & 9500 & 1798 \\
YVR & Vancouver & 13 & 11,500 & 7300 \\
YYC & Calgary & 3606 & 14,000 & 8000 \\
YZF & Yellowknife & 675 & 7500 & 5000 \\
YXE & Saskatoon & 1654 & 8300 & 6200 \\
YWG & Winnipeg & 783 & 11,000 & 8700 \\
YFB & Iqaluit & 110 & 8605 & - \\
YYZ & Toronto & 569 & 11,050 & 10,775 \\
YUL & Montréal & 118 & 11,000 & 7000 \\
YFC & Fredericton & 67 & 8005 & 6000 \\
YYG & Charlottetown & 159 & 7000 & 5000 \\
YHZ & Halifax & 447 & 10,500 & 7700 \\
YYT & St. John's & 46 & 8502 & 5028 \\
\hline
\end{tabular}

Table 2. Average annual itinerant movements (i.e., takeoff and landing) for the 2014-2018 period for three categories of aircrafts from Statistics Canada [38] (from busiest to least busy). Itinerant movements, expressed as percentage of total movements, are also included. Data for Iqaluit Airport and Charlottetown Airport was not available.

\begin{tabular}{ccccccc}
\hline & \multicolumn{5}{c}{ Maximum Takeoff Weight } \\
\cline { 2 - 6 } IATA & $\mathbf{1 8 , 0 0 0}$ kg and under & $\mathbf{1 8 , 0 0 1}$ to $\mathbf{9 0 , 0 0 0 ~ k g}$ & $\mathbf{9 0 , 0 0 1 ~ k g ~ a n d ~ o v e r ~}$ \\
\cline { 2 - 6 } & Movements & Percentage & Movements & Percentage & Movements & Percentage \\
\hline YYZ & 59,521 & $13 \%$ & 334,764 & $74 \%$ & 61,047 & $13 \%$ \\
YVR & 107,623 & $33 \%$ & 181,317 & $56 \%$ & 35,263 & $11 \%$ \\
YUL & 42,303 & $19 \%$ & 162,062 & $71 \%$ & 22,967 & $10 \%$ \\
YYC & 54,523 & $23 \%$ & 174,879 & $72 \%$ & 11,975 & $5 \%$ \\
YWG & 47,535 & $43 \%$ & 56,711 & $51 \%$ & 6297 & $6 \%$ \\
YHZ & 24,839 & $32 \%$ & 50,277 & $64 \%$ & 3707 & $5 \%$ \\
YYT & 19,756 & $46 \%$ & 22,447 & $52 \%$ & 934 & $2 \%$ \\
YXE & 37,626 & $59 \%$ & 25,171 & $40 \%$ & 607 & $1 \%$ \\
YFC & 51,361 & $90 \%$ & 5780 & $10 \%$ & 22 & $0 \%$ \\
YZF & 24,460 & $55 \%$ & 19,704 & $45 \%$ & 14 & $0 \%$ \\
YXY & 14,466 & $73 \%$ & 5251 & $27 \%$ & 41 & $0 \%$ \\
\hline
\end{tabular}

In this study, a weight restriction day is defined as a day with daily maximum temperature higher than a pre-defined temperature threshold (i.e., the temperature at which a given category of aircraft can take off with MTOW for a given location and current runway lengths). We only investigate the case of the longest runway at each airfield in this study. Table 3 shows the temperature thresholds for the three categories of aircraft for the studied airfields. These thresholds are based on the most commonly 
used aircraft at the studied airfields for categories 1 and 2 (i.e., Boeing 787-800 and Boeing 737-800, respectively), and are obtained from the corresponding performance charts [39,40]. Temperature thresholds for category 3 aircraft are obtained from the Federal Aviation Administration [41], which contain standard performance charts for category 3 type aircraft models for the studied airfields.

Table 3. Temperature thresholds used to estimate weight restriction days for studied airfields. "N/A" means the aircraft cannot takeoff at MTOW at any temperature because of a relatively short runway.

\begin{tabular}{cccc}
\hline IATA & Category $\mathbf{1}\left({ }^{\circ} \mathbf{C}\right)$ & Category $\mathbf{2}\left({ }^{\circ} \mathbf{C}\right)$ & Category $\mathbf{3}\left({ }^{\circ} \mathbf{C}\right)$ \\
\hline YYZ & 30 & 45 & 43.3 \\
YVR & 30 & 45 & 43.3 \\
YUL & 30 & 45 & 43.3 \\
YYC & - & 23 & 29 \\
YHZ & - & 45 & 43.3 \\
YWG & - & 40 & 43.3 \\
YXE & - & 26 & 43.3 \\
YXY & - & 26 & 38 \\
YZF & - & 30 & 37.8 \\
YFB & - & 35 & 43.3 \\
YFC & - & 30 & 40.5 \\
YYT & - & 30 & 43.3 \\
YYG & - & N/A & 34.4 \\
\hline
\end{tabular}

Following Es and Karwal [42], crosswind larger than 15 knots $(7.7 \mathrm{~m} / \mathrm{s})$ and tailwind larger than $5 \mathrm{knots}(2.6 \mathrm{~m} / \mathrm{s})$ are analyzed, as they are potentially considered too windy for takeoff or landing, particularly for light aircraft models that belong to category 3. Tailwind larger than $10 \mathrm{knots}(5.1 \mathrm{~m} / \mathrm{s})$ is also analyzed as they can cause overrun accidents [4,43]. According to the regulations of the International Civil Aviation Organization (ICAO) [43], the usability of a runway must be no less than $95 \%$ with maximum allowable crosswind conditions. Similarly, if the runway is wet or contaminated, no tailwind component ( $0-3$ knots considered as calm) must be present [44]. The tailwind and crosswind analyses are performed for the longest runway at the various airports considered (Figure 1b), using 3-hourly wind data simulated by GEM. The wind components along and perpendicular to the runway constitute tailwind and crosswind, respectively. The possibility of takeoff in both directions is considered in estimating tailwind. The probability of high crosswind and tailwind events is obtained by dividing the number of 3-hourly crosswind and tailwind events exceeding respective thresholds by the total number of 3-hourly crosswind and tailwind events for the selected 30-year periods.

\subsection{Approaches}

Validation of GEM simulated variables of interest is performed first by comparing GEM-ERAInterim with available observations for the 1981-2010 period. Boundary forcing errors are also assessed by comparing GEM-CanESM2 with GEM-ERAInterim for the same current period. Ensemble averages of GEM-CanESM2 are used for temperature, while for wind, 3-hourly wind data from the five GEM-CanESM2 members are merged for analysis.

Projected changes to maximum daily temperature are studied for three future periods (2011-2040, 2041-2070, and 2071-2099) with respect to the current 1981-2010 period of the GEM-CanESM2 simulations, for RCP 4.5 and 8.5 scenarios, in an effort to quantify emission uncertainties. Evolution of weight restriction days and weight restriction hours for the warmest and coolest periods of a day are then analyzed by considering 30-year moving windows for RCP8.5 and RCP4.5 scenarios for the studied airports. Projected changes to the probability of occurrence of crosswind and tailwind components are also analyzed using the merged 3-hourly wind data, for the same three future periods as for daily maximum temperature. 


\section{Results}

\subsection{Validation}

Previous studies [45] have validated GEM extensively and; therefore, only validation of variables relevant to this study (i.e., daily maximum temperature for summer and annual three-hourly wind characteristics) are presented here.

\subsubsection{Daily Maximum Temperature}

Before validating the model simulations, the observation datasets are compared for the 1981-2010 period to understand uncertainties in observations. Comparison of ERA-Interim and ERA5 shows more spatial structure in the latter, especially over the mountainous regions due to the higher resolution of ERA5 (Figure 2a). Comparison with point observations at the airfields shows that ERA5 is in better agreement with point observations compared to ERA-Interim, suggesting clear improvements brought by the higher resolution of ERA5 (Figure 2a). GEM-ERAInterim generally captures the spatial patterns, but suggests some underestimation for the western regions of Canada, when compared with ERA5. GEM-ERAInterim simulated temperatures are in better agreement with observations and ERA5 than ERA-Interim for most of the studied airfields (Figure 2b), suggesting added value in downscaling ERA-Interim. To detect boundary forcing errors (i.e., error due to the driving GCM data), GEM-CanESM2 is compared with GEM-ERAInterim, which suggests warmer temperatures in GEM-CanESM2. This is due to the warm bias of the driving CanESM2 model. For interannual variability, GEM-ERAInterim patterns show overall agreement with ERA5 and ERA-Interim, particularly for northern Canada, with some differences noted for the mid-central regions. However, GEM-CanESM2 shows generally smaller standard deviation than other simulations.

(a)

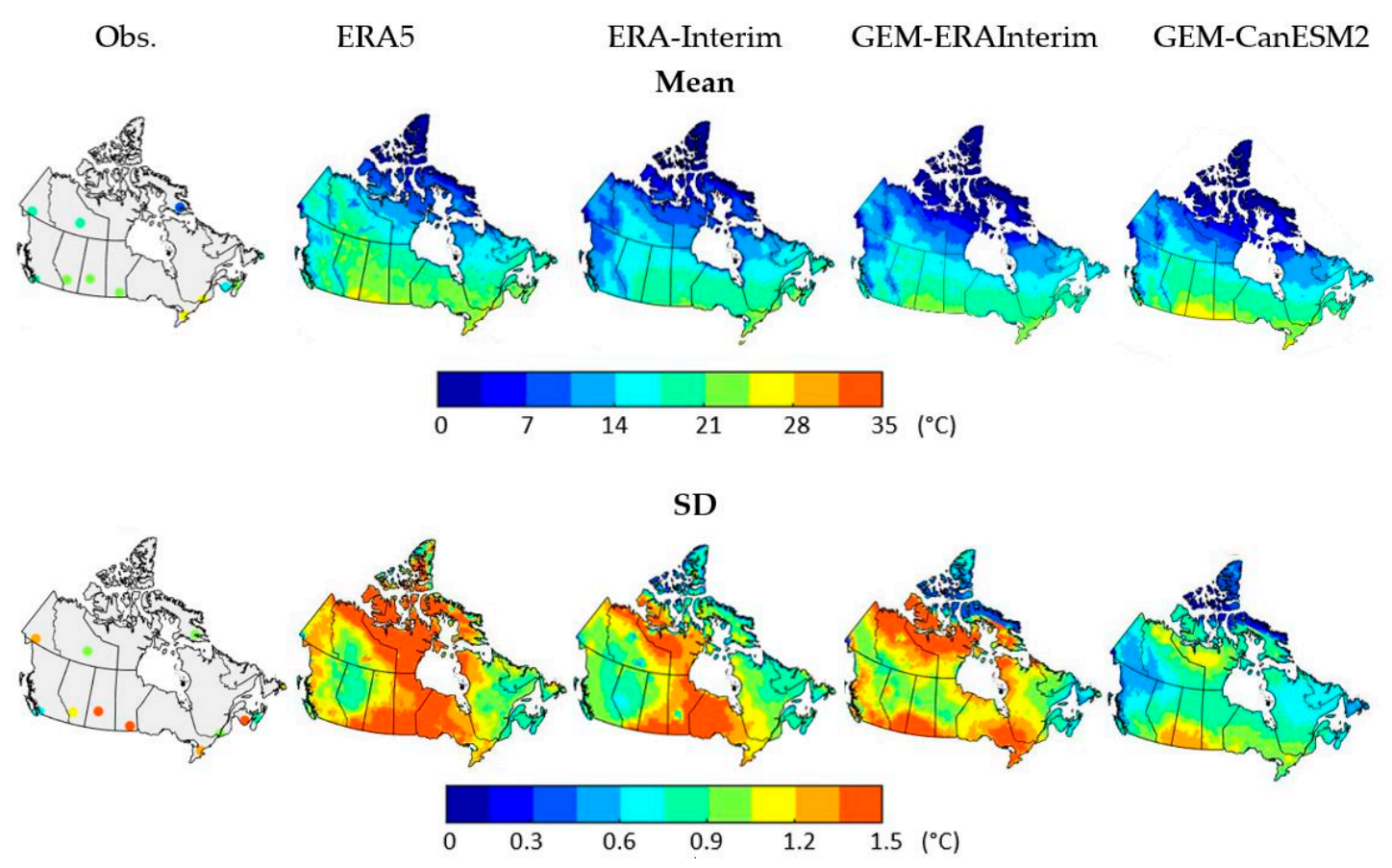

Figure 2. Cont. 
(b)

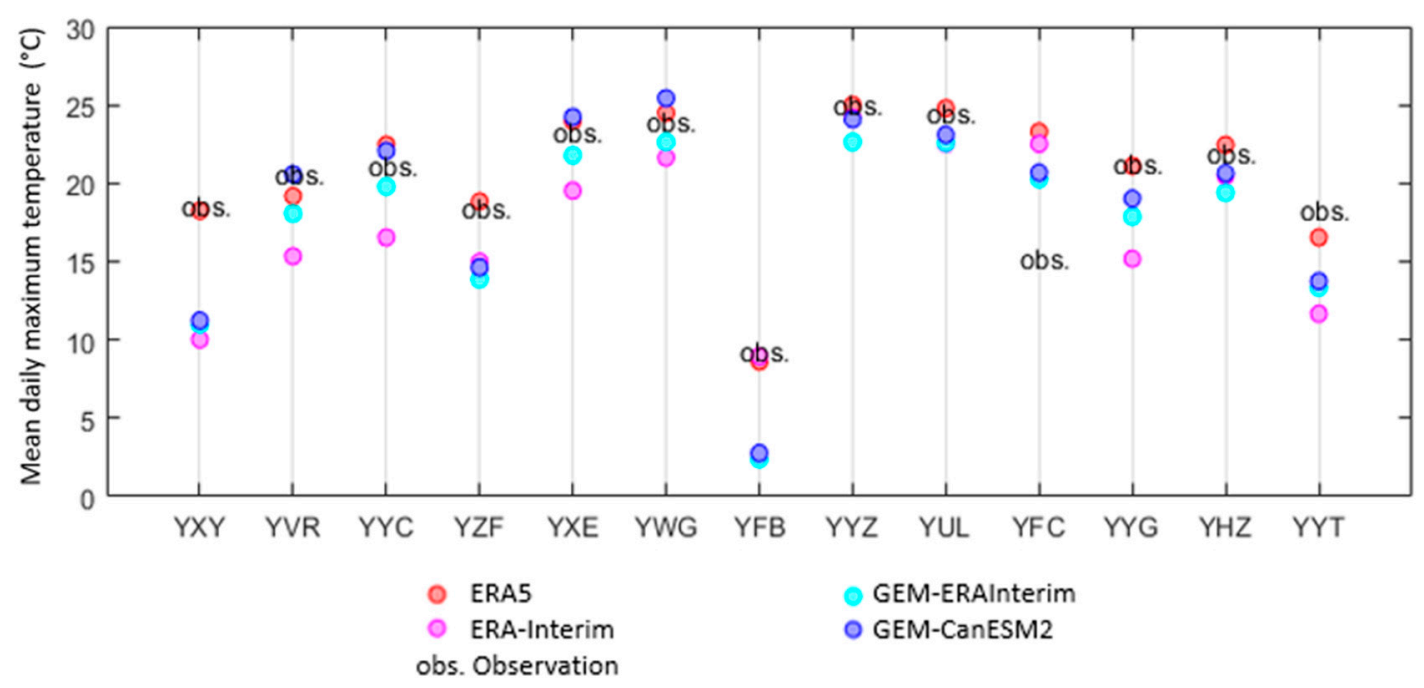

Figure 2. (a) Spatial plots of mean and standard deviation (SD) and (b) point (airfield) values of mean of daily maximum $2 \mathrm{~m}$ temperature for summer (JJA) from observations, ERA5 reanalysis, ERA-Interim reanalysis, GEM-ERAInterim, and GEM-CanESM2, for the 1981-2010 period.

\subsubsection{Wind}

Mean annual, summer (JJA), and winter (DJF) wind magnitudes simulated by GEM are validated by comparing with point observations from studied airfields and reanalysis datasets. Figure 3a shows lower wind speeds for the mountainous areas of western Canada for ERA5 compared to ERA-Interim, which is again due to the higher spatial resolution of ERA5. The point/airfield observations generally have larger wind magnitudes than ERA5, as expected. This is because the roughness lengths are generally smaller for airports, yielding higher wind magnitudes. Wind magnitudes for the mountainous western regions are improved in GEM-ERAInterim compared to ERA-Interim, which demonstrates added value of downscaling ERA-Interim. GEM-CanESM2 is generally in good agreement with GEM-ERAInterim, suggesting less influence of boundary forcing data. Comparison of $10 \mathrm{~m}$ mean annual wind magnitudes at the studied airfields (Figure 3b) suggests underestimation of wind magnitudes in the $0.5-1.8 \mathrm{~m} / \mathrm{s}$ range in GEM-ERAInterim when compared to point observations for the western airfields, while the underestimation is in the $0.2-1 \mathrm{~m} / \mathrm{s}$ range for the central airfields. Both under and overestimations are noted for the eastern airfields with differences generally less than $1 \mathrm{~m} / \mathrm{s}$.

The wind roses from ERA5 for the airfields exhibit similar patterns to that of point observations (Figure 4), except for Calgary and Yellowknife. The temporal resolution of the two data are the same (i.e., hourly) and the differences noted are primarily because ERA5 provides average values for the grid cell. Differences can; therefore, be large for regions with important orography and/or water bodies. Comparison of the wind roses (Figure 4) at the airport locations with the most representative grid cells from the simulations suggest overall agreement, albeit the larger directional spread and reduced magnitudes for GEM-ERAInterim, which can be partly due to the coarse temporal (three-hourly) and spatial resolution of data. As already mentioned, topographical effects are strong if the observation station is nearby mountains or open water bodies [46]. It must be noted that the point observations may also be subject to biases depending on the accuracy and sensitivity of the anemometer [37], especially for the case of weak and strong winds [47]. Wind roses from GEM-CanESM2 are not shown in Figure 4 as the patterns are very similar to that of GEM-ERAInterim. As for ERA5, ERA-Interim shows some important differences in wind roses for Calgary and Yellowknife, when compared to point observations. The direction is predominantly westerly in both ERA5 and GEM-ERAInterim for Calgary; however, observations also suggest southerly and northerly winds. As for Yellowknife, ERA5 and simulations do 
not capture the northerly direction in point observations. Overall, GEM simulations show agreement with ERA5 and are able to display the wind patterns at the airports.

The overall ability of GEM in simulating the observed characteristics of daily maximum temperatures and wind patterns suggest that the model can be applied to study future changes, with careful interpretation for regions with biases.

(a)

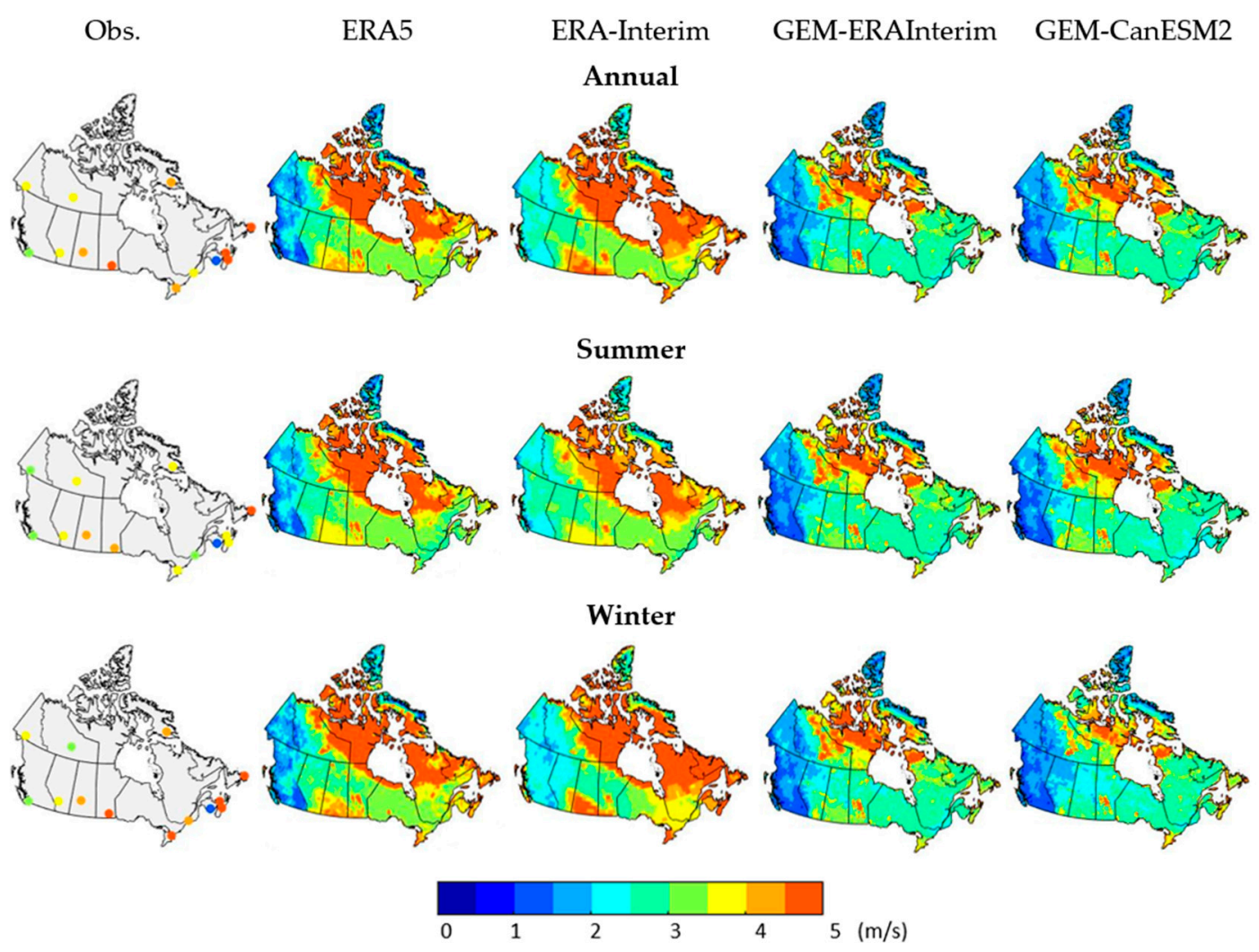

(b)

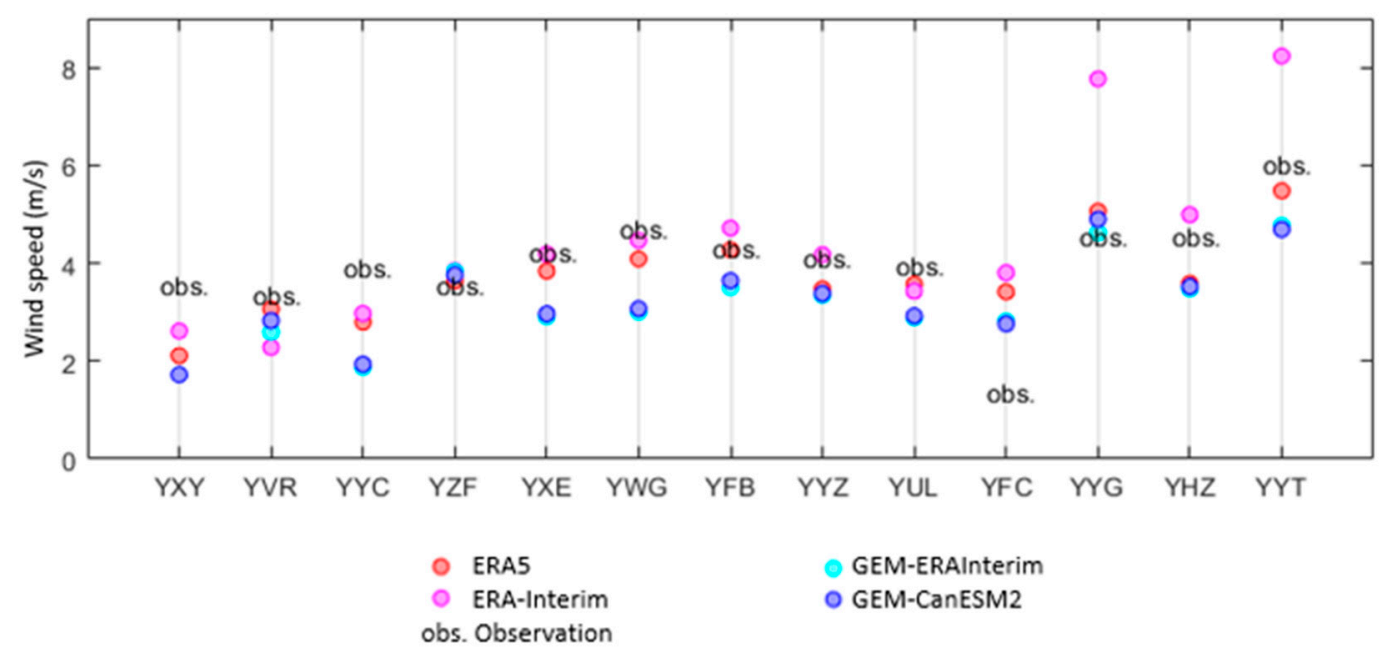

Figure 3. (a) Spatial plots of mean annual, summer and winter $10 \mathrm{~m}$ wind speeds and (b) point (airfield) values of $10 \mathrm{~m}$ mean annual wind speed for observations, ERA5 reanalysis, ERA-Interim reanalysis, GEM-ERAInterim and GEM-CanESM2, for the 1981-2010 period. 
Obs.

ERA5 GEM-ERAInterim

Obs.

ERA5 GEM-ERAInterim YXY, Whitehorse
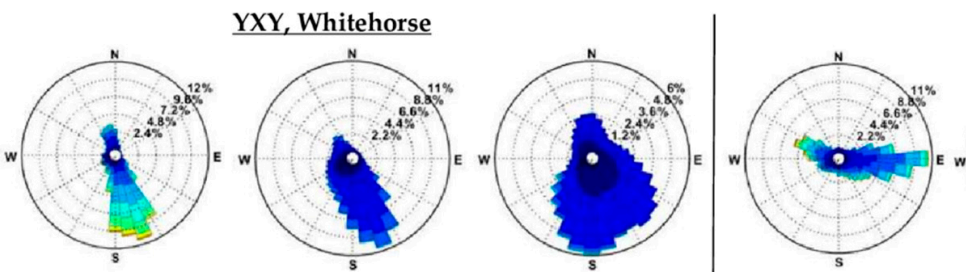

YVR, Vancouver

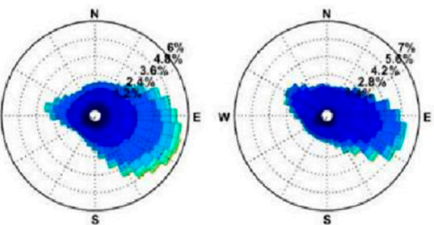

$\underline{\text { YYC, Calgary }}$
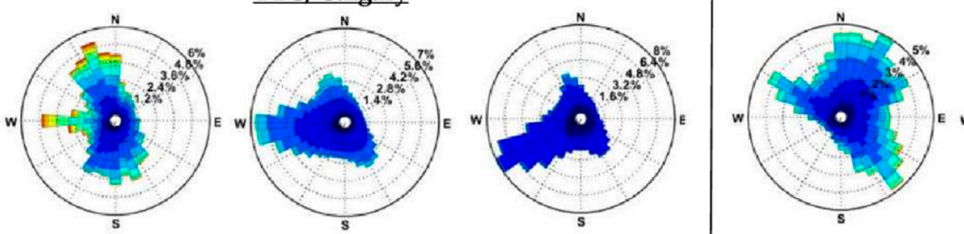

$\underline{\text { YZF, Yellowknife }}$
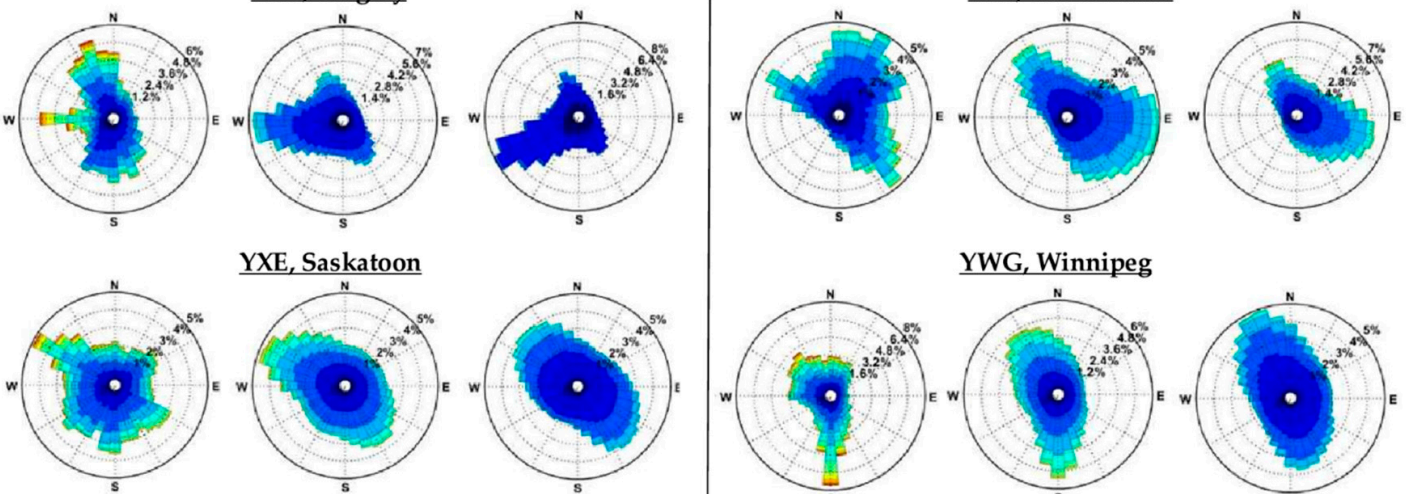

YXE, Saskatoon
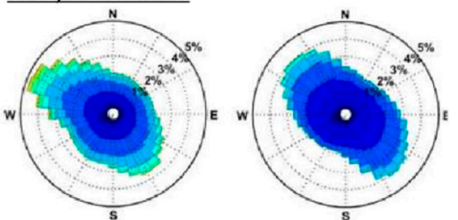

YWG, Winnipeg
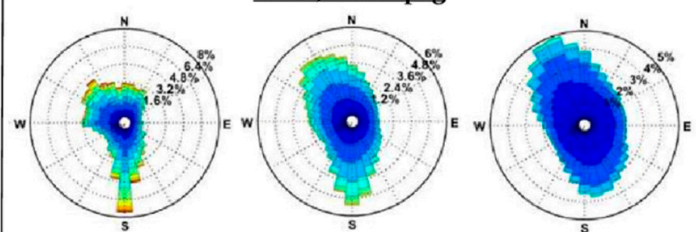

$\underline{\text { YFB, Iqaluit }}$
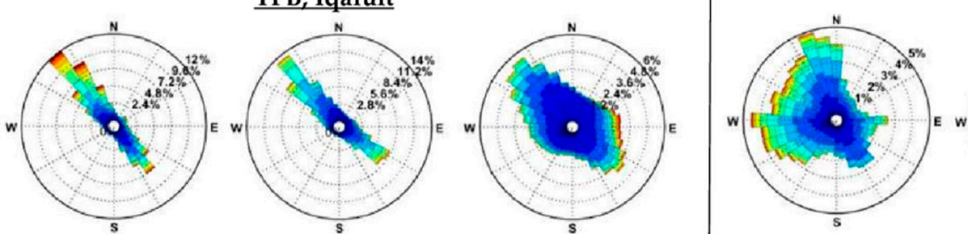

$\underline{\text { YYZ, Toronto }}$

\section{YUL, Montréal}
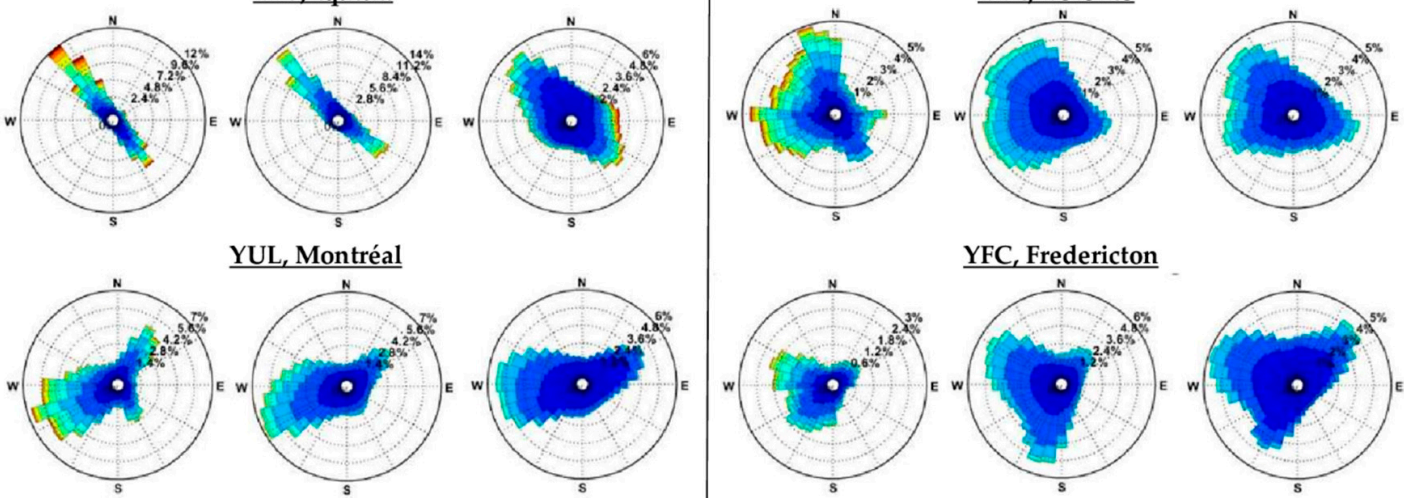

$\underline{\text { YFC, Fredericton }}$
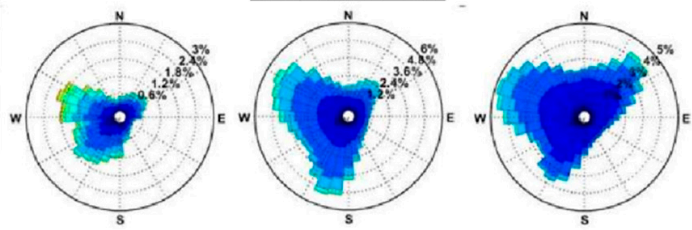

YYG, Charlottetown
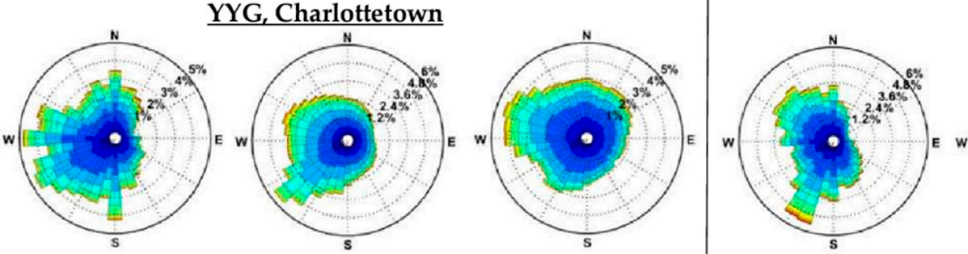

$\underline{\text { YHZ, Halifax }}$
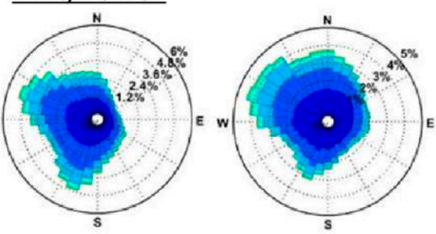

\section{$\underline{\text { YYT, St. John's }}$}
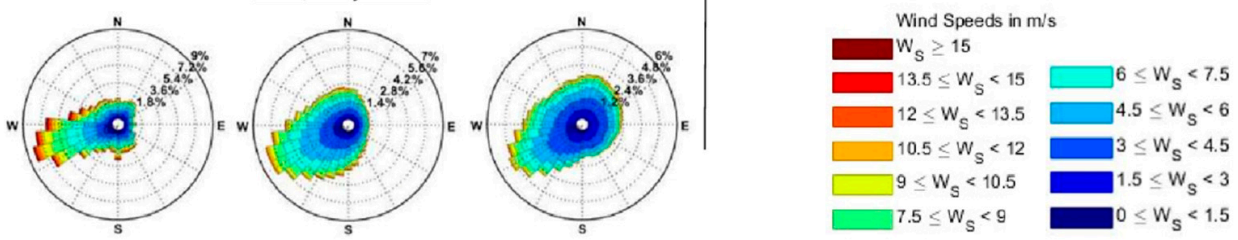

Figure 4. Distributions of wind direction and magnitude $(\mathrm{m} / \mathrm{s})$ from observations, ERA5 reanalysis and GEM-ERAInterim for the 1981-2010 period. Hourly wind magnitudes are considered for observations and ERA5, while three-hourly values are used for GEM-ERAInterim.

\subsection{Projected Changes}

\subsubsection{Daily Maximum Temperature and Weight Restriction Days/Hours}

The projected changes to mean daily maximum $2 \mathrm{~m}$ temperatures for the June to September period, shown in Figure 5, suggest increases of the order of 4 to $6{ }^{\circ} \mathrm{C}$ by the end of the century for RCP 
4.5 scenario, while for RCP 8.5 scenario, it is in the $7-10^{\circ} \mathrm{C}$ range across Canada. Most of the southern regions will experience daily maximum temperatures over $30^{\circ} \mathrm{C}$ on average, and they exceed $35^{\circ} \mathrm{C}$ for the inland regions of southwest Canada by the end of the century, where the average daily maximum temperature in summer is less than $25^{\circ} \mathrm{C}$ for the current climate. These changes can have significant impacts on aviation and aircraft takeoff performance.

(a)

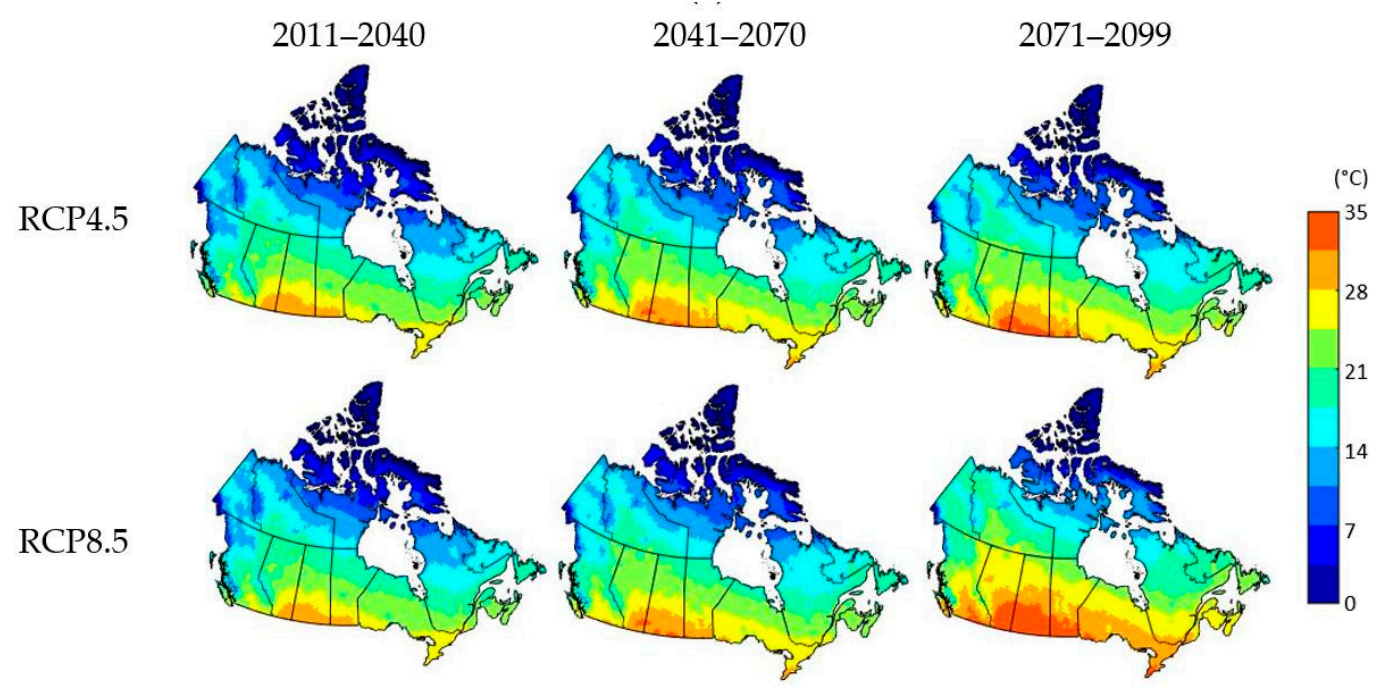

(b)

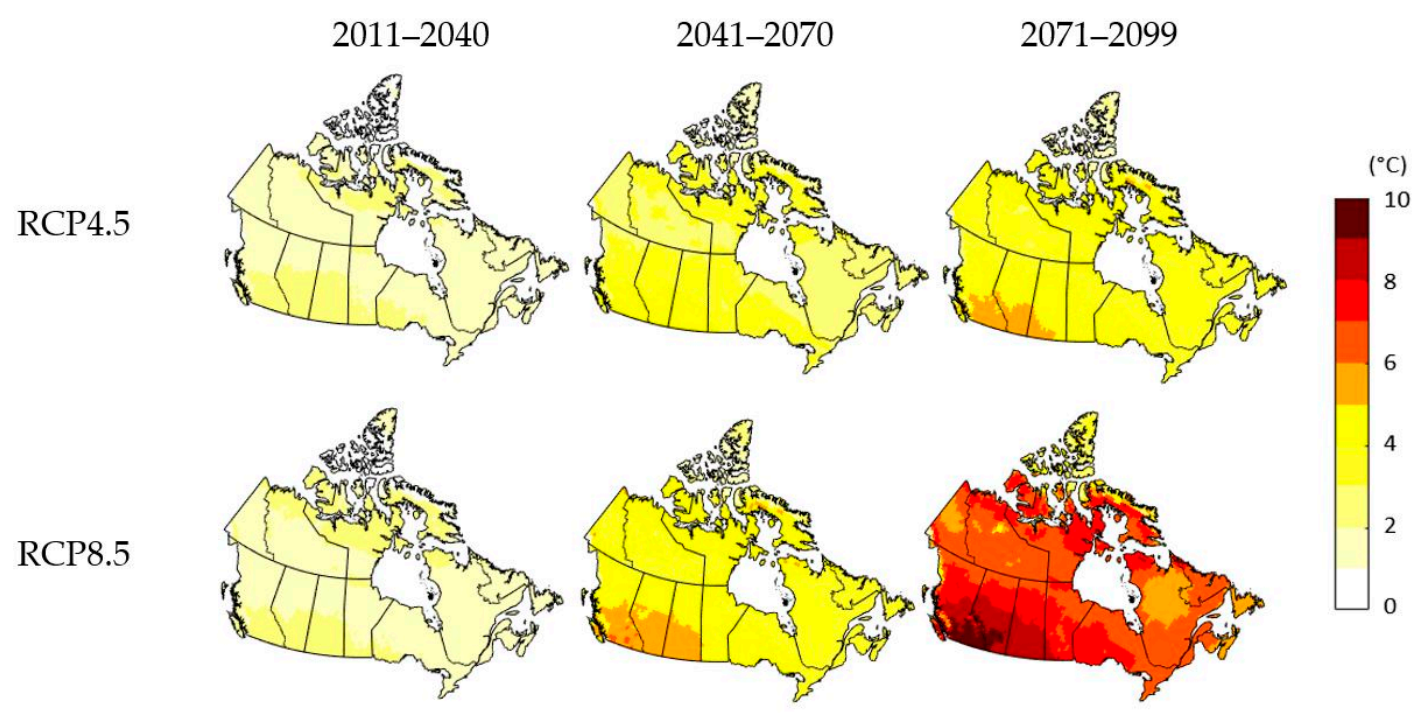

Figure 5. (a) Mean daily maximum temperature for summer (JJA) for the 2011-2040, 2041-2070 and 2071-2099 periods for RCP4.5 and RCP8.5 scenarios, and (b) their projected changes with respect to the 1981-2010 period.

The evolution of the mean number of weight restriction days for 30-year moving windows for different categories of aircraft for the summer period for the studied airports for RCP 4.5 and 8.5 scenarios are shown in Figure 6. Figure 6a shows the number of weight restriction days for category 1 aircraft for YYZ (Toronto), YVR (Vancouver) and YUL (Montreal); results for this category are not considered for other airfields since intercontinental flights are not common there. For the RCP8.5 scenario, all three airports will encounter weight restriction days after 2040. Weight restriction days are noted even towards the end of the current climate for YYZ; it must be noted that the warm bias in the GEM-CanESM2 
simulations can lead to slightly earlier detection of weight restriction days. By the end of the century, it will increase to around 70 days in summer for YYZ, and more than 40 days in YUL and YVR. For the RCP4.5 scenario, there are few weight restriction days in YVR in the future, and the number of weight restriction days are obviously lower than the ones for RCP8.5 during mid to late century.

(a) Category 1

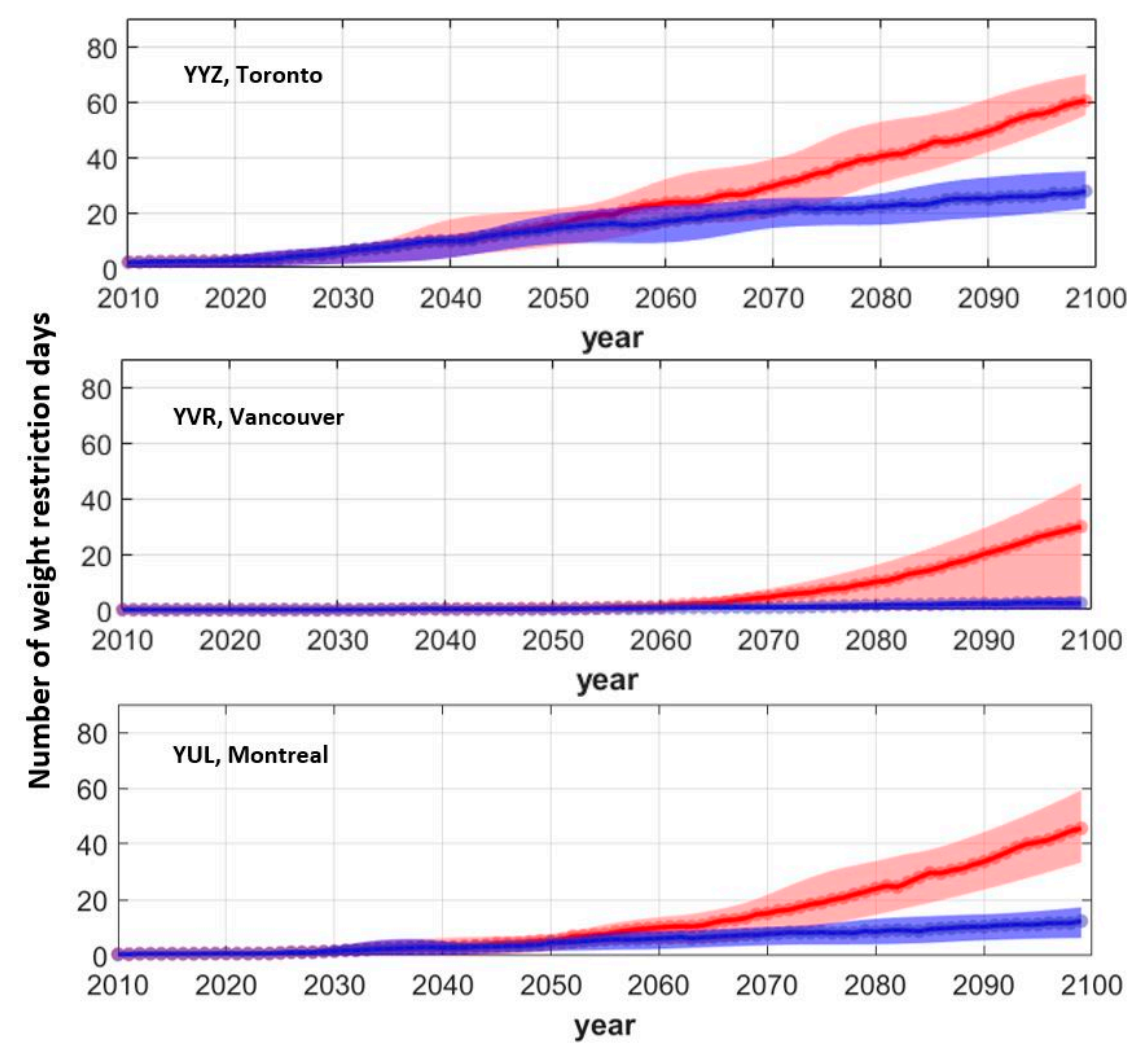

(b) Category 2

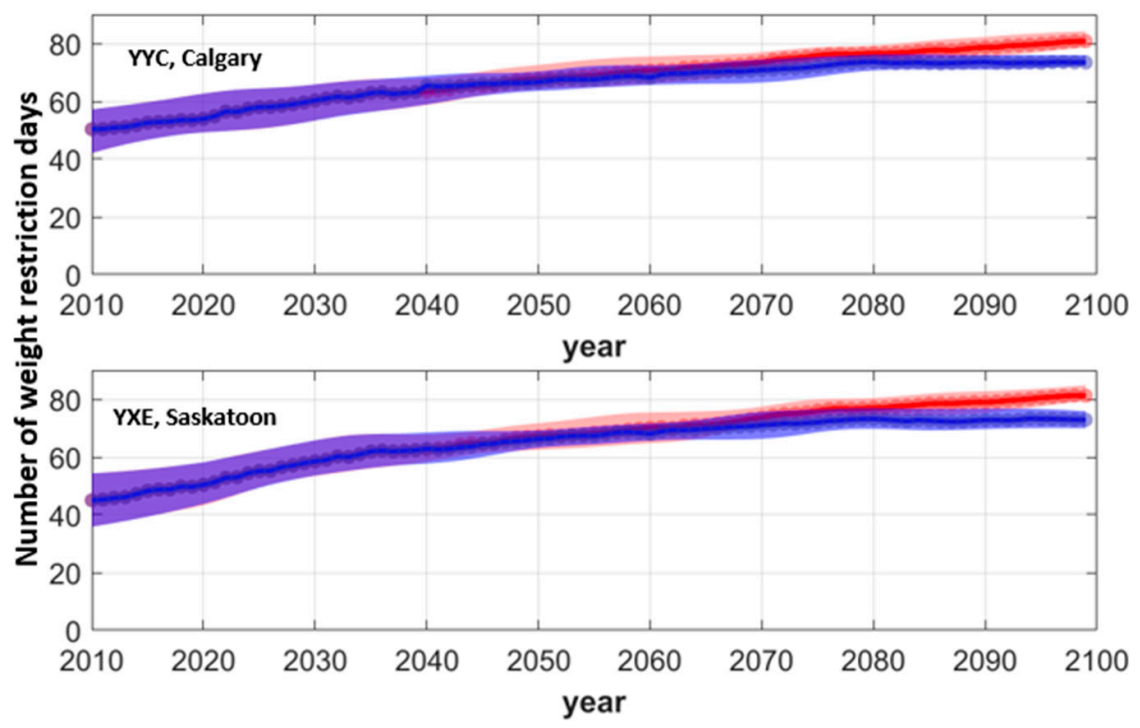

Figure 6. Cont. 
(c) Category 3

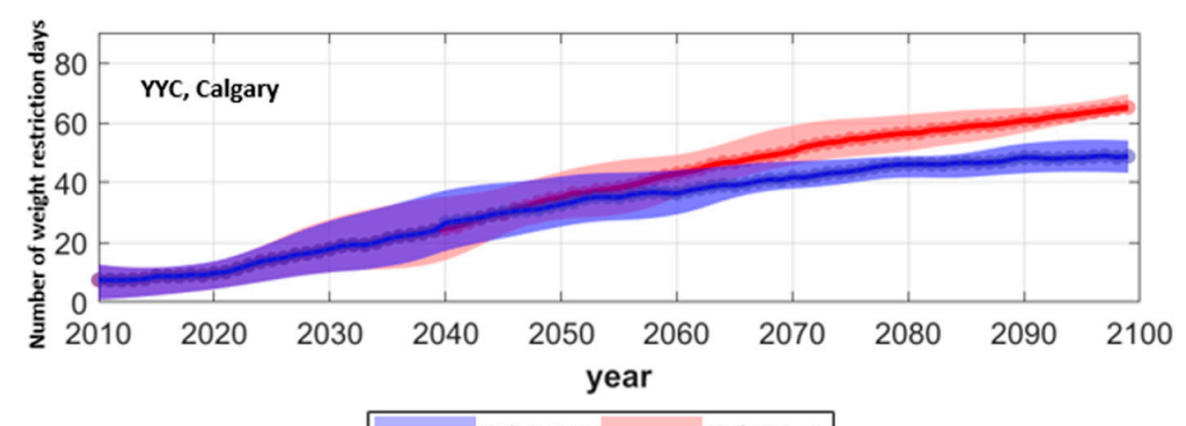

RCP4.5 RCP8.5

Figure 6. Average number of weight restriction days for 30-year moving windows for summer (JJA) for the 1981 to 2100 period for the RCP4.5 (in blue) and RCP8.5 (in red) scenarios for (a) category 1, (b) category 2, and (c) category 3 aircrafts. The mean values for 30-year widows are plotted at the end of the period, and the shaded region shows the interquartile range for respective windows. Results are shown only for airfields with weight restriction days.

For category 2 aircraft, Figure $6 \mathrm{~b}$ shows weight restriction even in current climate for YYC (Calgary) and YXE (Saskatoon). Weight restriction days increase for YYC and YXE and exceed 60 days by the end of the century for both scenarios, which is due to the higher projected increases in temperature and the relatively low temperature thresholds (due to high elevations) used to estimate weight restriction days. Weight restriction days appear only in the late century for Fredericton (YFC) and Winnipeg (YWG) for RCP8.5 (not shown). Weight restriction days for category 3 aircraft are noted only for YYC (Figure 6c), for both scenarios.

In reality, the scheduled takeoff for category 1 and 2 aircraft, being mostly long-range, are during morning and evening hours for some airfields. Therefore, they can still take off on weight restriction days at MTOW by avoiding the warmest period of the day. To better understand the impacts, analysis is performed for the warm (10:00 am to 7:00 pm local time) and cool (12:00 am to 10:00 am and 7:00 pm till 12:00 am combined) periods of the day. Weight restriction hours are estimated for these two periods for the airfields that experience significant weight restriction days in future climate. Figure 7 shows the average weight restriction hours for the summer period for 30-year moving windows. The results show large differences between the warmer and cooler periods.

For category 1 aircraft, the weight restriction hours during the warmer period of the day increases to more than three hours by the end of the century for YYZ for RCP8.5. Relatively smaller increases are noted for RCP4.5. Weight restriction hours during the cooler time of the day is rare in the future for both scenarios.

For category 2 aircraft, YXE and YYC experience a large number of weight restriction hours during the warmer period of the day even in the current climate, which increases to about $6-8 \mathrm{~h}$ by the end of the century for both scenarios. However, weight restriction hours during the cooler periods of the day show larger differences between RCP8.5 and RCP4.5, compared to the results for the warmest period of the day. This is because projected changes to daily minimum temperatures are larger than that for daily maximum temperatures, which is more predominant for RCP 8.5 scenario. Furthermore, the weight restriction hours seem to stabilize for RCP4.5 towards the end of the century, which is consistent with the changes in temperature.

The shaded region, showing the interquartile range, generally becomes thinner by the end of the century for both scenarios for the warmer period of the day as the temperature threshold is generally exceeded for most of the hours of the warmest period. This situation is not reached in the case of the coolest period and hence thinning of the interquartile range is not visible by the end of the century. 
(a) Category 1
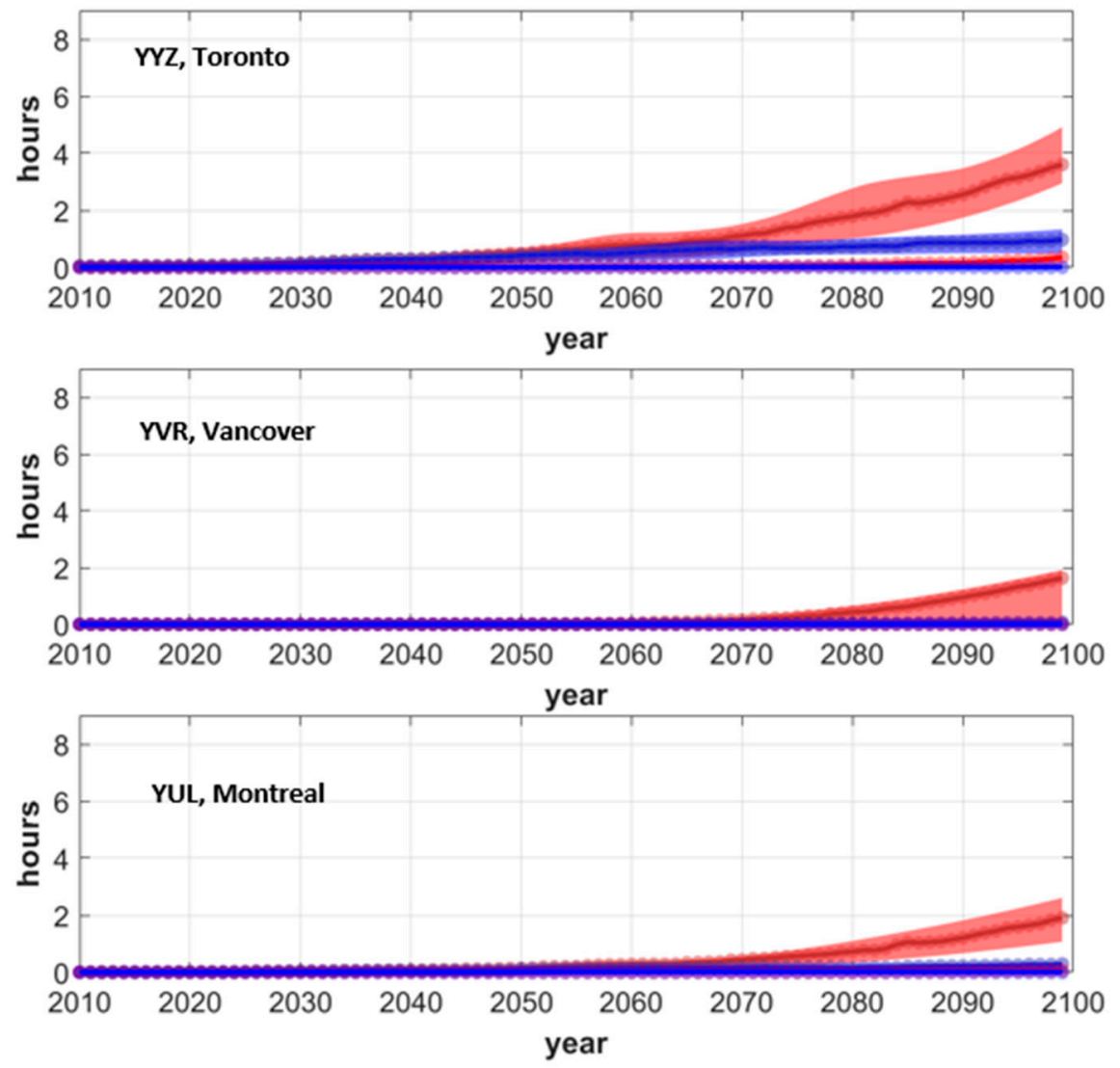

(b) Category 2
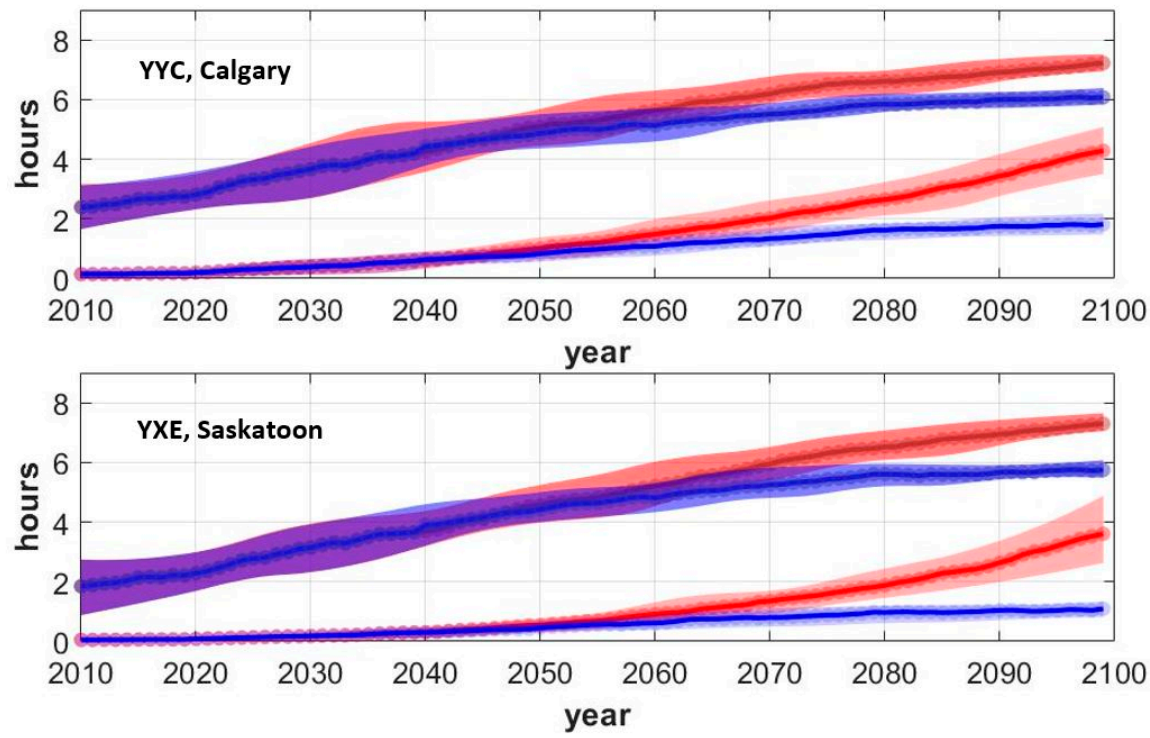

Figure 7. Cont. 
(c) Category 3

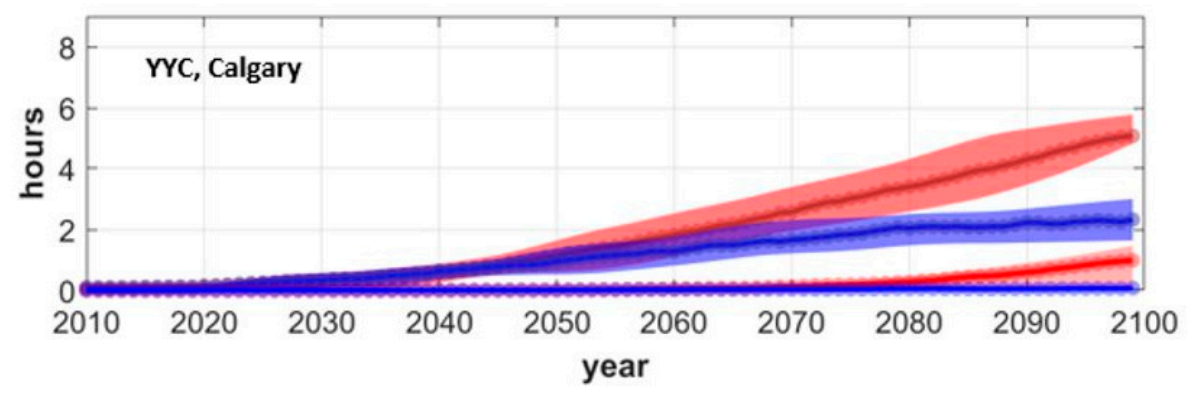

RCP4.5 warm period $=$ RCP8.5 warm period - RCP4.5 cooler period - RCP8.5 cooler period

Figure 7. Same as Figure 6, but shows weight restriction hours during the warmer (dark shades of red and blue) and cooler (light shades of red and blue) periods of the day.

For category 3 aircraft, some weight restriction hours are noted during the warmer periods of the day for YYC for RCP8.5. This is significantly smaller for RCP4.5. Much smaller increases are noted for the cooler period of the day.

\subsubsection{Crosswind and Tailwind}

Analysis of mean wind magnitudes for future climate suggests increases in wind magnitudes for northern regions of Canada for both scenarios, and decreases in eastern Canada for RCP8.5 by late century (Figure 8).

No major changes in wind directions for the studied airfields are noted (figure not shown). Figure 9 shows the probability of occurrence for crosswinds larger than 15 knots for the studied airfields. Results suggest that the probability of occurrence of crosswind larger than 15 knots is generally lower than $5 \%$, with relatively large values for northeastern airfields. Both increases and decreases are noted for future climate, with decreases noted mostly for the eastern regions, for both RCP 4.5 and 8.5 scenarios. For the northern regions, YFB (Iqaluit) shows consistent increases, while YZF (Yellowknife) and YXY (Whitehorse) show decreases. Majority of the southwest airfields shows increases in strong crosswinds.

The probability of the occurrence of tailwind larger than 5 and 10 knots shown in Figure 10 suggests that most of the studied airfields in the south have around $30 \%$ probability of experiencing tailwind larger than $5 \mathrm{knots}$, and exceeding 50\% in some airfields located in the northeast in the current climate. In future climate, the probability remains unchanged for RCP4.5. For RCP8.5, the projected changes suggest that the probability decreases consistently for most of the airfields in coastal areas across the three future periods. For airfields located in northern areas, the probabilities consistently increase, while they remain the same with slight fluctuations for the airfields in central regions. For tailwind thresholds larger than 10 knots, southern airfields generally have probabilities smaller than $5 \%$, and those for northern airfields are around 10\% in current climate. For the three future periods, there are some increases for northern airfields, whereas probabilities experience a larger decrease than for the case of the 5 knots threshold for southern Canada.

Overall, crosswind and tailwind probabilities remain unchanged or slightly decrease for most of the southeastern airfields with time but increase for northern and central airfields. The projected increases can impact aircraft operations leading to delays in future climate. For example, in Iqaluit, where only one runway exists, given the increases in the occurrence of high tailwinds in the future climate, from air traffic efficiency point of view, it will be beneficial to consider a crosswind runway. 
(a)

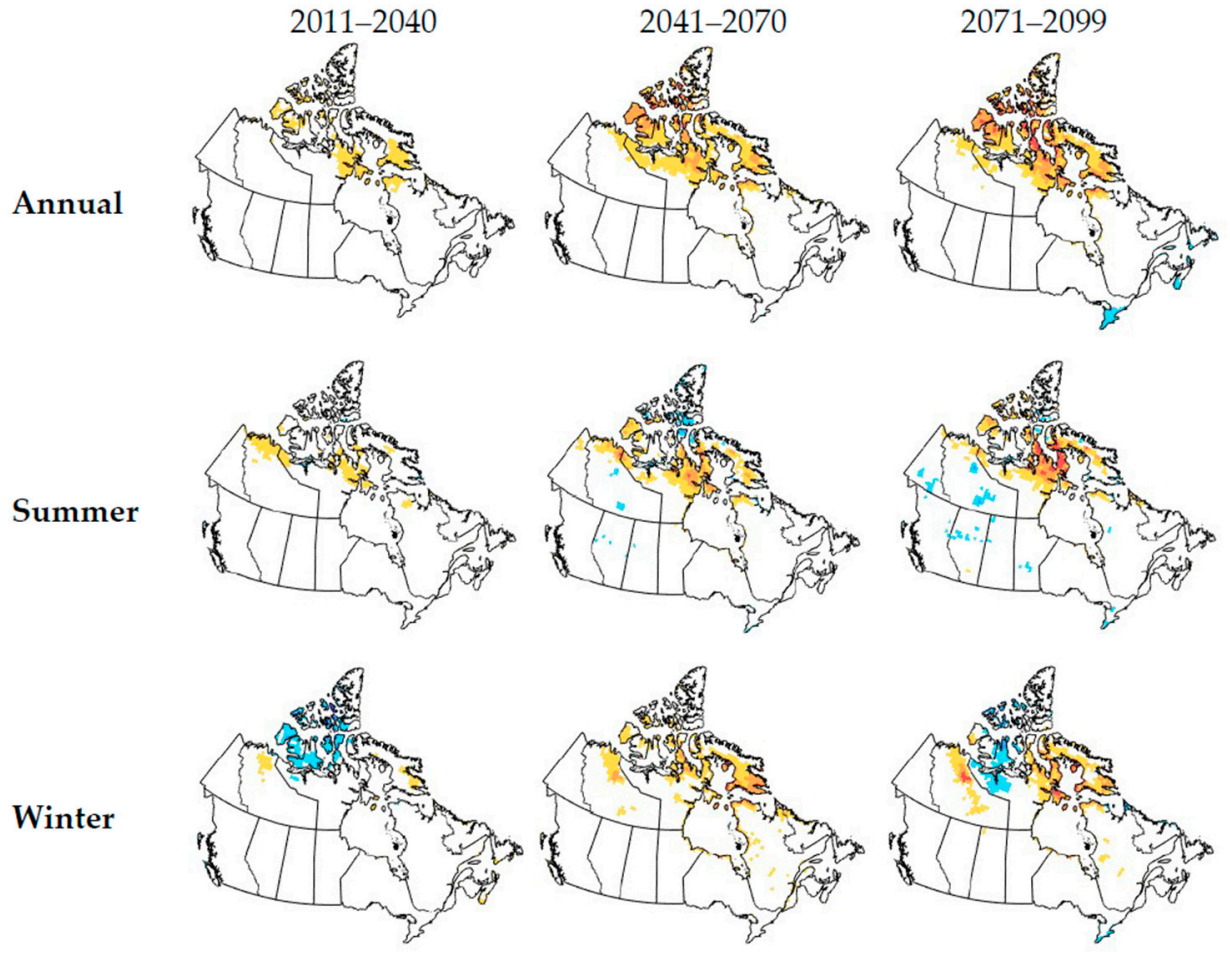

(b)

Annual
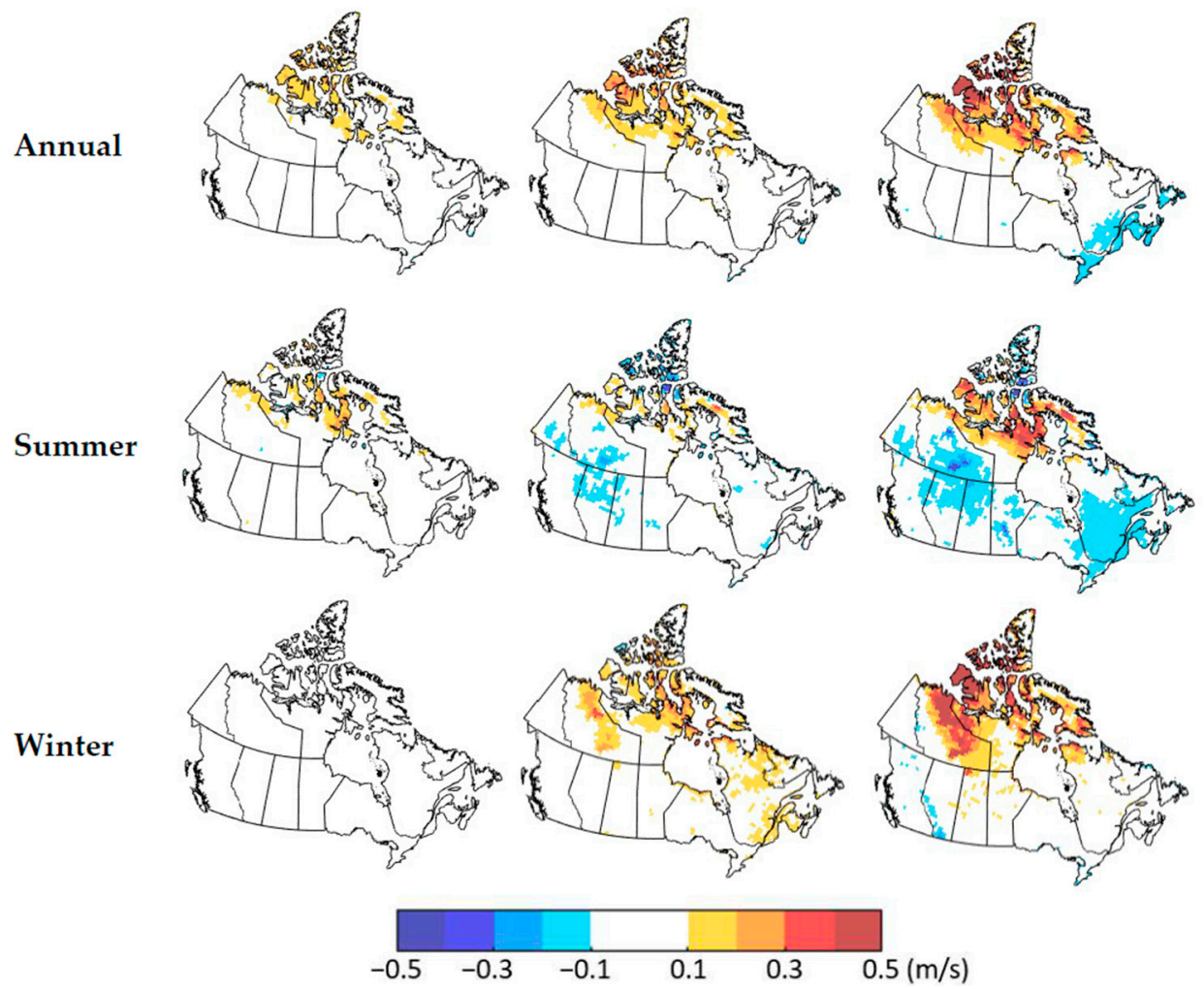

Figure 8. Projected changes to the mean annual, summer and winter $10 \mathrm{~m}$ wind magnitudes for the 2011-2040, 2041-2070 and 2071-2100 periods with respect to the current 1981-2010 period for (a) RCP 4.5 and (b) RCP 8.5 scenarios. 


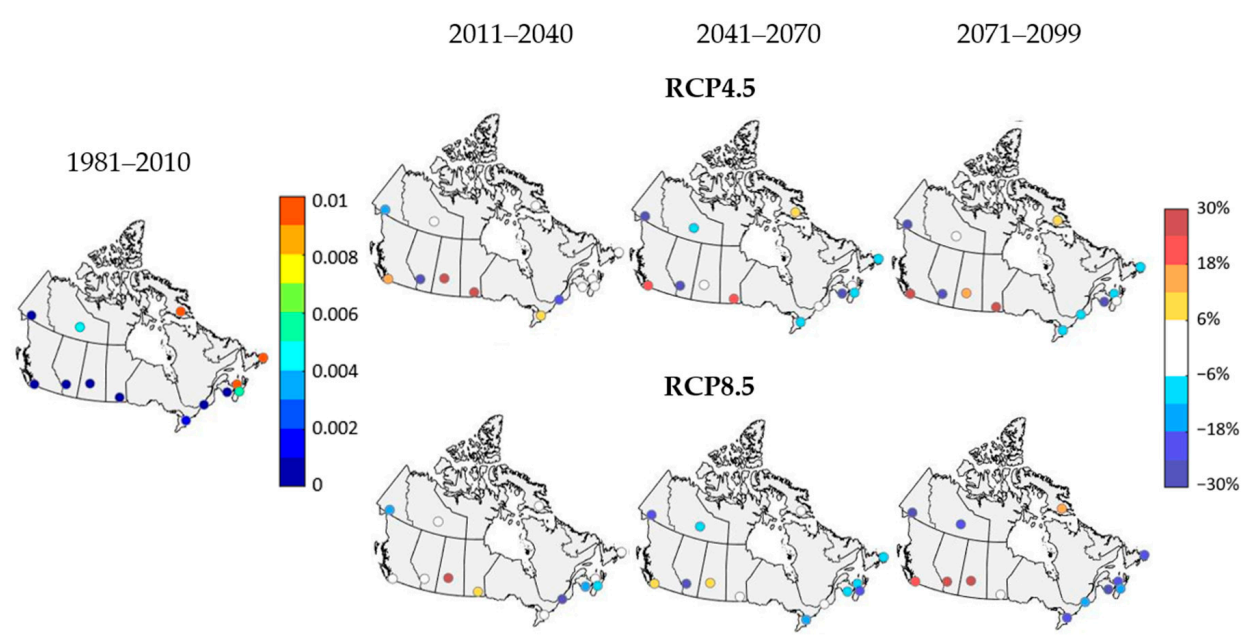

Figure 9. Probability of occurrence of crosswind larger than 15 knots for the longest runway for current climate (left), and their projected changes (in \%, right) for three future periods for RCP4.5 (top) and RCP8.5 (bottom) scenarios.

(a)

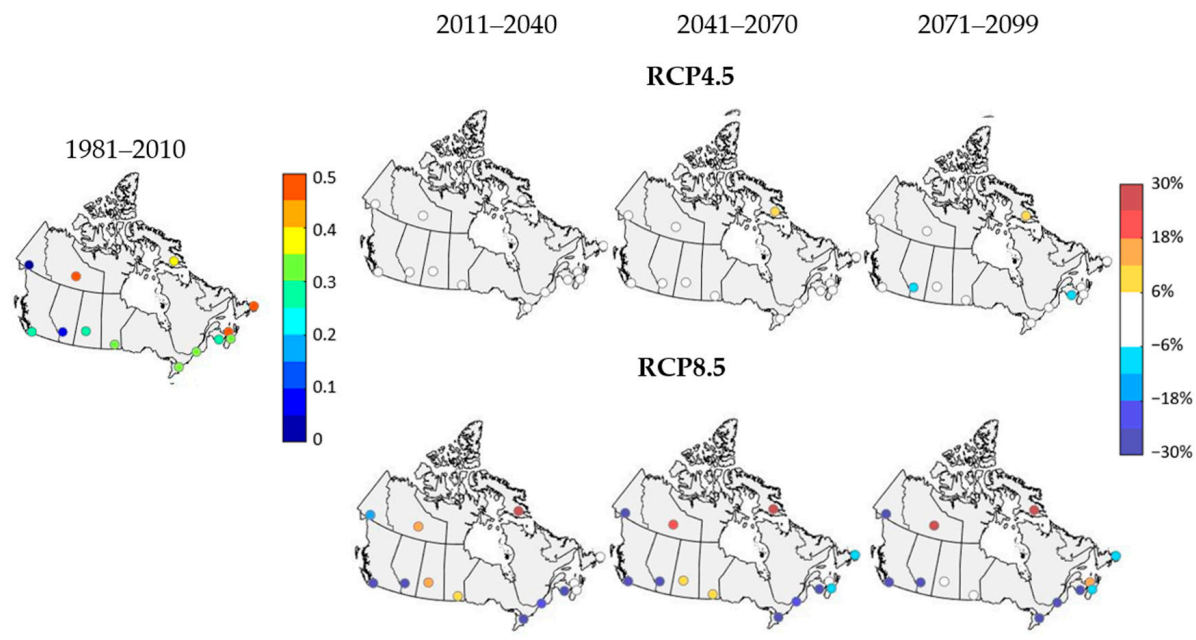

(b)

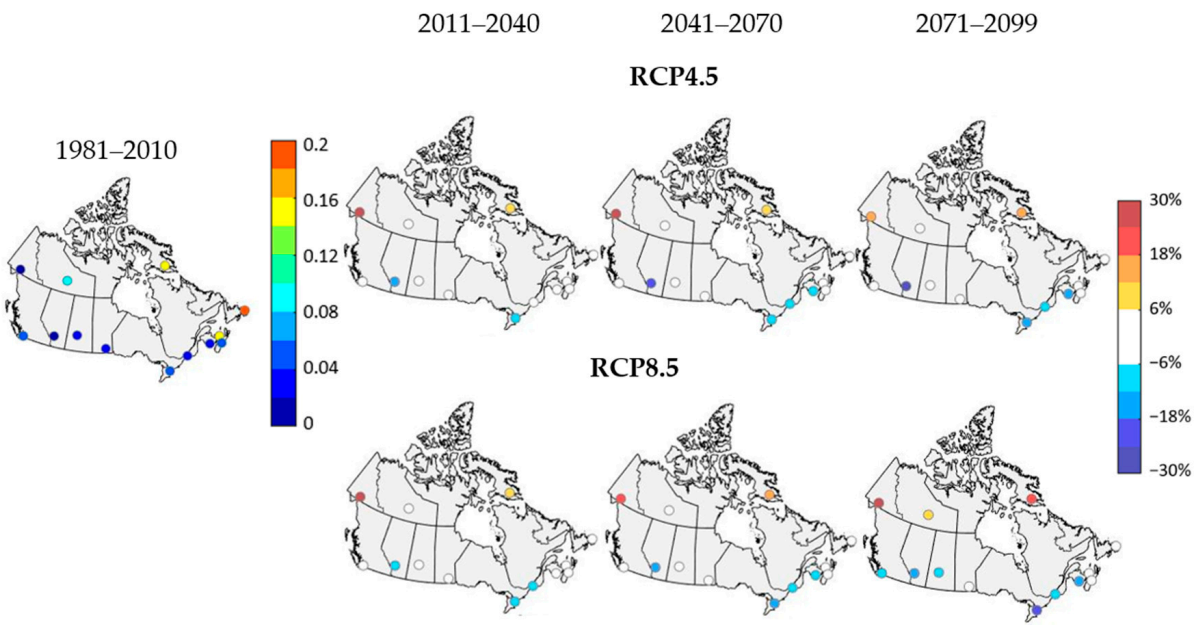

Figure 10. Same as Figure 9, but for tailwind larger than (a) 5 knots and (b) 10 knots. 


\section{Discussion and Conclusions}

This study evaluates projected changes to aircraft weight restriction days, and occurrences of crosswind and tailwind exceeding predefined thresholds that might affect aircraft takeoff performance for 13 airports across Canada. To this end, projected changes to summer daily maximum temperature, wind speed and wind directions, based on GEM simulations for the 1981 to 2100 period, driven by two five-member ensembles of CanESM2, corresponding to RCP4.5 and RCP8.5 emissions scenarios are analyzed. Validation of ERA-Interim-driven GEM simulation indicates that the model is able to reproduce the observed $10 \mathrm{~m}$ wind speed and near-surface temperature characteristics reasonably well, confirming the suitability of the model in assessing projected changes.

Projected changes to the summer daily maximum temperature suggest that weight restriction days for the three commonly used aircraft types (i.e., those used for long-, medium- and short-haul flights, referred to as category 1,2 and 3, respectively) will increase significantly by the end of the century for some of the studied airfields, especially those located at high elevations, such as Calgary and Saskatoon. For RCP4.5, the weight restriction days start to appear much later than for RCP8.5 scenario for low elevation airfields (i.e., for all except Calgary and Saskatoon). Additional analysis for the warmer and cooler periods of the day suggests that the weight restrictions are generally not applicable for cooler periods, except for Calgary and Saskatoon, for category 2 aircraft, with important differences noted between RCP4.5 and RCP8.5 scenarios.

It should be noted that the temperature thresholds used to determine the weight restriction days for the aircraft types are defined based on current runway lengths and MTOW, and can change if the aircraft operate with less than MTOW and if the runway lengths are extended, which again can be limited by the aircraft speed limit. The results related to the weight restriction days provide useful preliminary insights, which can inform aircraft takeoff scheduling and/or takeoff weights in future climate. For some short-haul flights, weight restriction can be solved by reducing the fuel weight. However, for long-haul flights, which require full capacity of the fuel tank, passengers and cargo have to be restricted if runway lengths are not extended. Other options such as changing aircraft type and making a stop for additional fuel can be considered. Changes in technology such as power off taxiing, just on time engine power ups and wings better designed for greater lift can also mitigate weight restriction in the future. The temperature threshold used in this study is based on the assumption of maximum takeoff power for the various categories of aircraft considered [39]. Furthermore, the real air temperature around the runway could be higher than that simulated by the model due to the lower albedo of the runway surfaces and surrounding buildings. To capture this better, ultra-high resolution climate simulations can be useful.

As for wind, the probability of strong tailwind and crosswind components are projected to decrease for the airports in the eastern region, while increases are noted for the northern and central airports, for both RCP scenarios. No significant changes are noted for the other airports. The crosswind and tailwind analyzed in this study can be used to re-evaluate runway orientation and length. For the northern airfields with increasing probability of tailwind, changing direction on the same runway can be considered as is generally done. However, if there are limitations to this, including those related to topography, planning for an alternate runway in the future could be an option to prevent accidents and delays. Additional analyses are required to guide such airport specific planning. Detailed studies using ultra-high resolution climate simulations focused over regions/airfields of interest coupled with site/runway level computational fluid dynamics modelling, to capture microclimatic conditions, should be undertaken to better inform decision-making and climate change adaptation planning.

Author Contributions: Conceptualization, Y.Z. and L.S.; methodology, Y.Z. and L.S.; validation, Y.Z.; formal analysis, Y.Z.; original draft preparation, Y.Z. and L.S.; manuscript review and editing, L.S. and Y.Z.; visualization, Y.Z.; funding acquisition, L.S. All authors have read and agreed to the published version of the manuscript.

Funding: This research was funded by the National Sciences and Engineering Research Council of Canada and the Trottier Institute for Sustainability in Engineering and Design. 
Acknowledgments: The GEM simulations used in this study were performed on the supercomputer managed by Compute Canada and Calcul Québec. This research was funded by the National Sciences and Engineering Research Council of Canada and the Trottier Institute for Sustainability in Engineering and Design. The authors would like to thank William Maynard of Transport Canada for reviewing an earlier version of the manuscript and for providing information about the studied airfields.

Conflicts of Interest: The authors declare no conflicts of interest.

\section{References}

1. Field, C.B.; Barros, V.; Stocker, T.F.; Qin, D.; Dokken, D.J.; Ebi, K.L.; Mastrandrea, M.D.; Mach, K.J.; Plattner, G.-K.; Allen, S.K.; et al. (Eds.) IPCC Managing the Risks of Extreme Events and Disasters to Advance Climate Change Adaptation: A Special Report of Working Groups I and II of the Intergovernmental Panel on Climate Change; Cambridge University Press: New York, NY, USA, 2012; p. 582.

2. Oster, C.V.; Strong, J.S.; Zorn, K. Why Airplanes Crash: Causes of Accidents Worldwide. In Proceedings of the 51st Annual Transportation Research Forum, Arlington, VA, USA, 11-13 March 2010.

3. Bureau of Transportation Statistics. Weather's Share of Delay as Percent of Total Delay-Minutes, by Year; United States Department of Transportation: Washington, DC, USA, 2019.

4. FAA. Pilot's Handbook of Aeronautical Knowledge; U.S. Department of Transportation, Federal Aviation Administration: Washington, DC, USA, 2008; p. 471.

5. Bellasio, R. Analysis of wind data for airport runway design. J. Airl. Airpt. Manag. 2014, 4. [CrossRef]

6. Coffel, E.; Horton, R. Climate change and the impact of extreme temperatures on aviation. Weather Clim. Soc. 2014, 7, 94-102. [CrossRef]

7. Coffel, E.D.; Thompson, T.R.; Horton, R.M. The impacts of rising temperatures on aircraft takeoff performance. Clim. Chang. 2017, 144, 381-388. [CrossRef]

8. Zhou, Y.; Zhang, N.; Li, C.; Liu, Y.; Huang, P. Decreased takeoff performance of aircraft due to climate change. Clim. Chang. 2018, 151, 463-472. [CrossRef]

9. Zhou, T.; Ren, L.; Liu, H.; Lu, J. Impact of $1.5^{\circ} \mathrm{C}$ and $2.0^{\circ} \mathrm{C}$ global warming on aircraft takeoff performance in China. Sci. Bull. 2018, 63, 700-707. [CrossRef]

10. Gratton, G.; Padhra, A.; Rapsomanikis, S.; Williams, P.D. The impacts of climate change on Greek airports. Clim. Chang. 2020. [CrossRef]

11. Williams, P.D. Transatlantic flight times and climate change. Environ. Res. Lett. 2016, 11, 024008. [CrossRef]

12. Williams, P.D. Increased light, moderate, and severe clear-air turbulence in response to climate change. Adv. Atmos. Sci. 2017, 34, 576-586. [CrossRef]

13. Lee, S.H.; Williams, P.D.; Frame, T.H.A. Increased shear in the North Atlantic upper-level jet stream over the past four decades. Nature 2019, 572, 639-642. [CrossRef]

14. Williams, P.D.; Joshi, M.M. Intensification of winter transatlantic aviation turbulence in response to climate change. Nat. Clim. Chang. 2013, 3, 644. [CrossRef]

15. Irvine, E.A.; Shine, K.P.; Stringer, M.A. What are the implications of climate change for trans-Atlantic aircraft routing and flight time? Transp. Res. Part D Transp. Environ. 2016, 47, 44-53. [CrossRef]

16. Bush, E.; Lemmen, D.S. (Eds.) Canada's Changing Climate Report; Government of Canada: Ottawa, ON, Canada, 2019; p. 444.

17. Zhang, X.; Vincent, L.A.; Hogg, W.D.; Niitsoo, A. Temperature and precipitation trends in Canada during the 20th century. Atmos. Ocean 2000, 38, 395-429. [CrossRef]

18. Jeong, D.I.; Sushama, L.; Diro, G.T.; Khaliq, M.N.; Beltrami, H.; Caya, D. Projected changes to high temperature events for Canada based on a regional climate model ensemble. Clim. Dyn. 2016, 46, 3163-3180. [CrossRef]

19. Jeong, D.I.; Sushama, L. Projected changes to extreme wind and snow environmental loads for buildings and infrastructure across Canada. Sustain. Cities Soc. 2018, 36, 225-236. [CrossRef]

20. Côté, J.; Desmarais, J.-G.; Gravel, S.; Méthot, A.; Patoine, A.; Roch, M.; Staniforth, A. The Operational CMC-MRB Global Environmental Multiscale (GEM) Model. Part II: Results. Mon. Weather Rev. 1998, 126, 1397-1418. [CrossRef]

21. Yeh, K.-S.; Côté, J.; Gravel, S.; Méthot, A.; Patoine, A.; Roch, M.; Staniforth, A. The CMC-MRB Global Environmental Multiscale (GEM) Model. Part III: Nonhydrostatic Formulation. Mon. Weather Rev. 2002, 130, 339-356. [CrossRef] 
22. Laprise, R. The Euler Equations of Motion with Hydrostatic Pressure as an Independent Variable. Mon. Weather Rev. 1992, 120, 197-207. [CrossRef]

23. Kain, J.S.; Fritsch, J.M. The role of the convective "trigger function" in numerical forecasts of mesoscale convective systems. Meteorol. Atmos. Phys. 1992, 49, 93-106. [CrossRef]

24. Bélair, S.; Mailhot, J.; Girard, C.; Vaillancourt, P. Boundary Layer and Shallow Cumulus Clouds in a Medium-Range Forecast of a Large-Scale Weather System. Mon. Weather Rev. 2005, 133, 1938-1960. [CrossRef]

25. Sundqvist, H.; Berge, E.; Kristjánsson, J.E. Condensation and Cloud Parameterization Studies with a Mesoscale Numerical Weather Prediction Model. Mon. Weather Rev. 1989, 117, 1641-1657. [CrossRef]

26. Li, J.; Barker, H.W. A Radiation Algorithm with Correlated-k Distribution. Part I: Local Thermal Equilibrium. J. Atmos. Sci. 2005, 62, 286-309. [CrossRef]

27. Benoit, R.; Côté, J.; Mailhot, J. Inclusion of a TKE Boundary Layer Parameterization in the Canadian Regional Finite-Element Model. Mon. Weather Rev. 1989, 117, 1726-1750. [CrossRef]

28. Delage, Y. Parameterising sub-grid scale vertical transport in atmospheric models under statically stable conditions. Bound. Layer Meteorol. 1997, 82, 23-48. [CrossRef]

29. Zadra, A.; McTaggart-Cowan, R.; Roch, M. Recent Changes to the Orographic Blocking; Seminar Presentation; RPN: Dorval, QC, Canada, 30 March 2012.

30. Verseghy, D. CLASS-The Canadian Land Surface Scheme (Version 3.4), Technical Documentation (Version 1.1); Climate Research Division, Science and Technology Branch, Environment Canada: Downsview, ON, Canada, 2009 ; p. 180.

31. Martynov, A.; Laprise, R.; Sushama, L.; Winger, K.; Šeparović, L.; Dugas, B. Reanalysis-driven climate simulation over CORDEX North America domain using the Canadian Regional Climate Model, version 5: Model performance evaluation. Clim. Dyn. 2013, 41, 2973-3005. [CrossRef]

32. Diro, T.G.; Sushama, L. Simulating canadian arctic climate at convection-permitting resolution. Atmosphere 2019, 10, 430. [CrossRef]

33. Dee, D.P.; Uppala, S.M.; Simmons, A.J.; Berrisford, P.; Poli, P.; Kobayashi, S.; Andrae, U.; Balmaseda, M.A.; Balsamo, G.; Bauer, P.; et al. The ERA-Interim reanalysis: Configuration and performance of the data assimilation system. Q. J. R. Meteorol. Soc. 2011, 137, 553-597. [CrossRef]

34. Arora, V.K.; Scinocca, J.F.; Boer, G.J.; Christian, J.R.; Denman, K.L.; Flato, G.M.; Kharin, V.V.; Lee, W.G.; Merryfield, W.J. Carbon emission limits required to satisfy future representative concentration pathways of greenhouse gases. Geophys. Res. Lett. 2011, 38. [CrossRef]

35. Mekis, E.; Donaldson, N.; Reid, J.; Zucconi, A.; Hoover, J.; Li, Q.; Nitu, R.; Melo, S. An Overview of Surface-Based Precipitation Observations at Environment and Climate Change Canada. Atmos. Ocean 2018, 56, 71-95. [CrossRef]

36. Hersbach, H.; Dee, D. ERA5 reanalysis is in production. ECMWF Newsl. 2016, 147, 5-6.

37. Wan, H.; Wang, X.L.; Swail, V.R. Homogenization and Trend Analysis of Canadian Near-Surface Wind Speeds. J. Clim. 2010, 23, 1209-1225. [CrossRef]

38. Statistics Canada. Table 23-10-0023-01 Itinerant Movements, by Aircraft Maximum Take-Off Weight, Airports with NAV CANADA Towers, Annual; Statistics Canada: Ottawa, ON, Canada, 2020. [CrossRef]

39. Boeing. 737 Airplane Characteristics for Airport Planning; Boeing Commercial Airplanes: Seattle, WA, USA, 2013; p. 682.

40. Boeing. 787 Airplane Characteristics for Airport Planning; Boeing Commercial Airplanes: Seattle, WA, USA, 2018; p. 180.

41. FAA. Runway Length Requirements for Airport Design (Advisory Circular 150/5325-4B); U.S. Department of Transportation, Federal Aviation Administration: Washington, DC, USA, 2005; p. 38.

42. Es, G.W.H.V.; Karwal, A.K. Safety aspects of tailwind operations. In Proceedings of the Flight Safety Foundation Annual European Aviation Safety Seminar, Amsterdam, The Netherlands, 12-14 March 2001.

43. ICAO. Annex 14 to the Convention on International Civil Aviation Aerodromes, 8th ed.; International Civil Aviation Organization: Montréal, QC, Canada, 2018; Volume Areodrome Design and Operations; p. 354.

44. FAA. National Safety and Operational Criteria for Runway Use Programs Document Information; U.S. Department of Transportation, Federal Aviation Administration: Washington, DC, USA, 1981; p. 8. 
45. Teufel, B.; Sushama, L.; Huziy, O.; Diro, G.T.; Jeong, D.I.; Winger, K.; Garnaud, C.; de Elia, R.; Zwiers, F.W.; Matthews, H.D.; et al. Investigation of the mechanisms leading to the 2017 Montreal flood. Clim. Dyn. 2019, 52, 4193-4206. [CrossRef]

46. Wieringa, J. Representativeness of Wind Observations at Airports. Bull. Am. Meteorol. Soc. 1980, 61, 962-971. [CrossRef]

47. Azorin-Molina, C.; Asin, J.; McVicar, T.R.; Minola, L.; Lopez-Moreno, J.I.; Vicente-Serrano, S.M.; Chen, D. Evaluating anemometer drift: A statistical approach to correct biases in wind speed measurement. Atmos. Res. 2018, 203, 175-188. [CrossRef]

(C) 2020 by the authors. Licensee MDPI, Basel, Switzerland. This article is an open access article distributed under the terms and conditions of the Creative Commons Attribution (CC BY) license (http://creativecommons.org/licenses/by/4.0/). 